\title{
Identification and Validation of Potential New Biomarkers for Prostate Cancer Diagnosis and Prognosis Using 2D-DIGE and MS
}

\author{
Cordelia Geisler, ${ }^{1}$ Nadine T. Gaisa, ${ }^{1}$ David Pfister, ${ }^{2}$ Susanne Fuessel, ${ }^{3}$ \\ Glen Kristiansen, ${ }^{4}$ Till Braunschweig, ${ }^{1}$ Sonja Gostek, ${ }^{1}$ Birte Beine, ${ }^{5,6}$ Hanna C. Diehl, ${ }^{5}$ \\ Angela M. Jackson, ${ }^{7}$ Christoph H. Borchers, ${ }^{7,8}$ Axel Heidenreich, ${ }^{2}$ Helmut E. Meyer, ${ }^{5,6}$ \\ Ruth Knüchel, ${ }^{1}$ and Corinna Henkel ${ }^{1,5,6}$ \\ ${ }^{1}$ Institute of Pathology, RWTH Aachen University, 52074 Aachen, Germany \\ ${ }^{2}$ Department of Urology, RWTH Aachen University, 52074 Aachen, Germany \\ ${ }^{3}$ Department of Urology, University Hospital Carl Gustav Carus, 01307 Dresden, Germany \\ ${ }^{4}$ Institute of Pathology, University Hospital Bonn (UKB), 53127 Bonn, Germany \\ ${ }^{5}$ Medizinisches Proteom-Center, Ruhr-University Bochum, 44801 Bochum, Germany \\ ${ }^{6}$ Leibniz-Institut für Analytische Wissenschaften ISAS e.V., 44139 Dortmund, Germany \\ ${ }^{7}$ University of Victoria-Genome British Columbia Proteomics Centre, University of Victoria, Victoria, BC, Canada V8Z 7X8 \\ ${ }^{8}$ Department of Biochemistry and Microbiology, University of Victoria, Victoria, BC, Canada V8W $2 Y 2$
}

Correspondence should be addressed to Corinna Henkel; corinna.henkel@isas.de

Received 7 March 2014; Revised 5 September 2014; Accepted 5 September 2014

Academic Editor: Andreas Doll

Copyright (C) 2015 Cordelia Geisler et al. This is an open access article distributed under the Creative Commons Attribution License, which permits unrestricted use, distribution, and reproduction in any medium, provided the original work is properly cited.

\begin{abstract}
This study was designed to identify and validate potential new biomarkers for prostate cancer and to distinguish patients with and without biochemical relapse. Prostate tissue samples analyzed by 2D-DIGE (two-dimensional difference in gel electrophoresis) and mass spectrometry (MS) revealed downregulation of secernin-1 $(P<0.044)$ in prostate cancer, while vinculin showed significant upregulation $(P<0.001)$. Secernin-1 overexpression in prostate tissue was validated using Western blot and immunohistochemistry while vinculin expression was validated using immunohistochemistry. These findings indicate that secernin-1 and vinculin are potential new tissue biomarkers for prostate cancer diagnosis and prognosis, respectively. For validation, protein levels in urine were also examined by Western blot analysis. Urinary vinculin levels in prostate cancer patients were significantly higher than in urine from nontumor patients $(P=0.006)$. Using multiple reaction monitoring-MS (MRM-MS) analysis, prostatic acid phosphatase (PAP) showed significant higher levels in the urine of prostate cancer patients compared to controls $(P=0.012)$, while galectin-3 showed significant lower levels in the urine of prostate cancer patients with biochemical relapse, compared to those without relapse $(P=0.017)$. Three proteins were successfully differentiated between patients with and without prostate cancer and patients with and without relapse by using MRM. Thus, this technique shows promise for implementation as a noninvasive clinical diagnostic technique.
\end{abstract}

\section{Introduction}

Prostate cancer is the most commonly occurring cancer among men in economically developed countries. In 2008, 62 out of 100,000 men were diagnosed with the disease [1]. Worldwide, 248,500 men died of prostate cancer in 2008 [1], although most men diagnosed with prostate cancer die from causes other than prostate cancer [2]. Some prostate cancers are clinically relevant from the start, while others will acquire clinical significance over the years $[3,4]$. High-grade prostatic intraepithelial neoplasia often develops into prostate cancer [5-7], although many prostate cancers may remain indolent for 10-15 years or longer [8]. Today, the "gold standard" for the treatment of prostate cancer is prostatectomy, but 
approximately one-third of all prostatectomy patients will develop a "biochemical relapse" $[9,10]$, which is defined as the elevation of prostate specific antigen (PSA). Almost $100 \%$ of patients who show a biochemical relapse will later develop a clinical relapse [11], with metastasis ultimately causing death $[12,13]$.

Today, prostate cancer is most often diagnosed through positive palpatory findings within a digital rectal examination and/or a high PSA value during PSA-screening; although specificity is low [14-16], histopathological findings from punch biopsies are used for verification. These findings together with clinical data are used for prognosis using so called "nomograms" [17], whereas the accuracy is only $70 \%$ $[18,19]$. Even postoperative nomograms have accuracies of only $75 \%[18,19]$.

PSA is a suitable biomarker to identify recurrent prostate cancer subsequent to treatment. However, PSA remains questionable as a diagnostic and prognostic marker [20-23], because specificity and sensitivity are low for the current diagnostic cutoff levels of $4 \mathrm{ng} / \mathrm{mL}$ [24]. Unfortunately, high levels of blood PSA ( $>4 \mathrm{ng} / \mathrm{mL}$ ) are not necessarily caused by the presence of prostate cancer [24]. PSA can be elevated due to inflammation, benign prostate hyperplasia $(\mathrm{BPH})$, and/or infections [25-27]. Moreover, 70\% of patients with PSA $>4 \mathrm{ng} / \mathrm{mL}$ and $<10 \mathrm{ng} / \mathrm{mL}$ do not actually have prostate cancer, while $5 \%$ with PSA $<0.5 \mathrm{ng} / \mathrm{mL}$ actually do have prostate cancer [24]. On the other hand, patients who are diagnosed with prostate cancer are often overtreated [28], as many prostate cancers are indolent, and because reliable biomarkers for the aggressive form of the disease are currently not available. Thus, new biomarkers are urgently needed.

Proteomic approaches are very promising for the discovery of new biomarkers (as reviewed in [29]). 2D-DIGE (twodimensional difference gel electrophoresis) is an accurate method for the relative quantitation of human proteins, as this technique reduces intergel variability and simplifies gel analysis of small sample amounts [30, 31].

Unfortunately, despite intense research, no clinical biomarker panel for recurrent prostate cancer is available yet as most published biomarkers for prostate cancer are limited to the discovery phase, are still waiting for validation, or could not be validated in independent studies [32]. A huge problem is the availability of prostate cancer patients' tissue. Many prostate cancer biomarker studies used suboptimal sample sets where samples in the study groups were not matched to age, stage, or grade, tissues were not dissected into tumor and tumor-free tissue, or there were not enough followup data available. As an example Pang et al. analyzed lymph node metastatic prostate cancer and benign prostate cancer tissue using 2D-DIGE and MALDI-TOF/TOF-MS to identify potential new biomarker candidates for lymph node metastatic prostate cancer [33]. Unfortunately, the sample sets were not matched with regard to patients' age, tumor stage, and tumor grade. Other studies are working with tissue samples of patients, which already have metastasis at the time of biopsy $[34,35]$. Unfortunately, comparison of those retrospective samples does not forcibly lead to biomarkers which are useful to stratify patients without recurrence at the time of diagnosis. Further limitations of publicized studies are the use of a 2D-DIGE minimal labeling system (e.g., $[33,36]$ ), which is not suitable for the detection of proteins with low abundance. Therefore, in the present study, a 2D-DIGE saturation labeling system was used, allowing labeling of $1.000-5.000$ cells $[37,38]$ or 0,5 fmol protein [39] whereby this sensitivity could not be reached by other techniques so far [40].

Multiple reaction monitoring (MRM) is a mass spectrometry technique that provides accurate absolute quantitation of selected proteotryptic peptides [41]. For the most accurate quantitation, a synthetic stable isotope-labelled (SIS) peptide at a known concentration is spiked into the sample. Quantitation of the natural peptide takes place through comparison of the peaks from the natural and the chemically identical SISpeptides. MRM has been shown to fulfill the requirements needed for the verification of biomarker candidates, as it has the capability to quantify proteins consistently, simultaneously, accurately, and reproducibly in complex samples [41]. Compared to ELISA, lead time is shorter and costs are reduced [41]. As an example, Percy et al. and Domanski et al. have developed multiplexed MRM-based assays for the quantitation of cardiovascular disease biomarkers and cancer biomarkers in human plasma $[42,43]$. Until now, these assays are developed to fulfill the requirements for preclinical application for evaluating potential useful biomarkers [42]. But hopefully, MRM-based methods for quantitation of cancer-related protein biomarkers will soon be approved by the US FDA [42], moving this technique one step closer to clinical application [44].

In the present study, patients sample sets for both analyzed patient groups (patients with biochemical relapse versus patients without biochemical relapse) were matched with regard to age, tumor stage, and tumor grade as far as possible. Additionally, manual microdissection of the tissue ensures that the percentage of tumor glands in the analyzed tissue were $>80 \%$.

Potential new prostate cancer biomarkers were found in a 2D-DIGE study of prostate cancer tissues from patients with and without relapse, with tumor-free tissue samples as controls. The deregulated proteins were identified using mass spectrometry (MS). Ingenuity pathway analyses were accomplished in order to perform functional analysis of the identified proteins. Promising potential biomarker candidates were chosen for further validation with immunohistochemical staining of an independent tissue microarray, Western blots of tissue and urine proteins, and MRM-MS analysis of patients' urine. The detailed study design is shown in Figure 1.

\section{Material and Methods}

\subsection{Analysis of Tissue Samples}

2.1.1. Clinical Specimens. Twelve cancer samples from prostatectomy specimens without relapse, 11 cancer samples with relapse, and 14 tumor free prostate samples corresponding to the tumor samples were analyzed with 2D-DIGE. The same samples were used for Western blot analysis. Where possible, matched patient samples with respect to age, tumor 


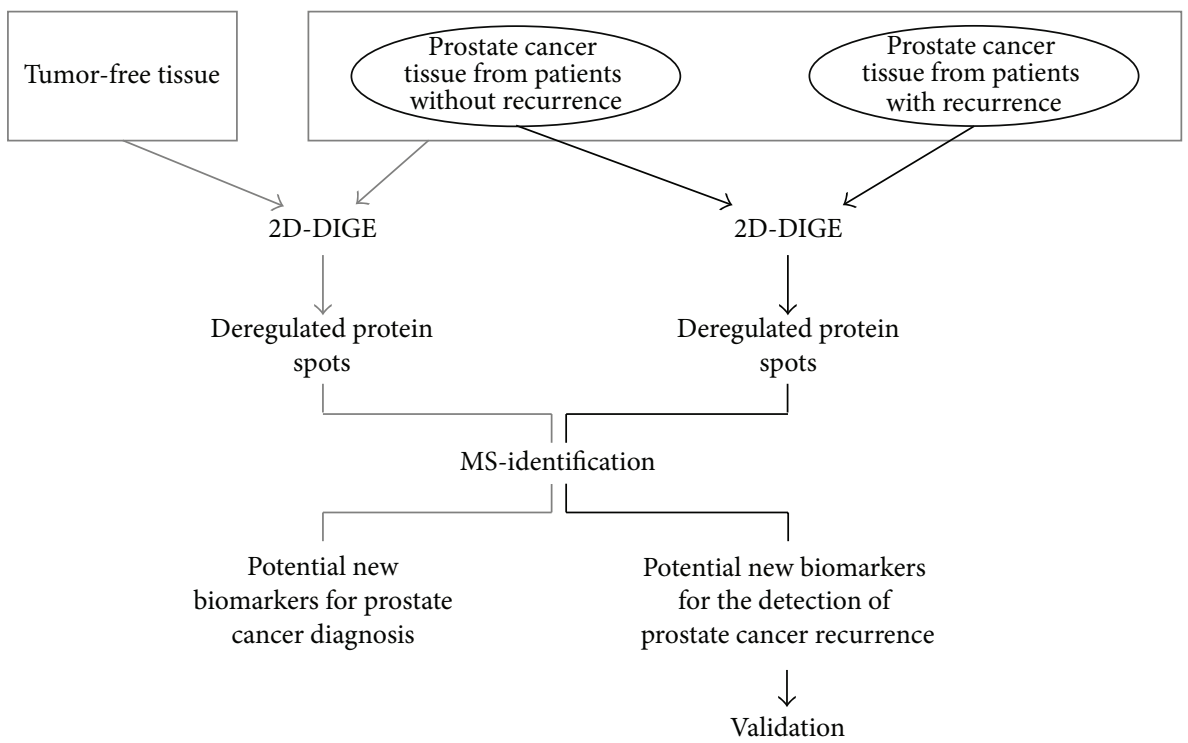

(a)
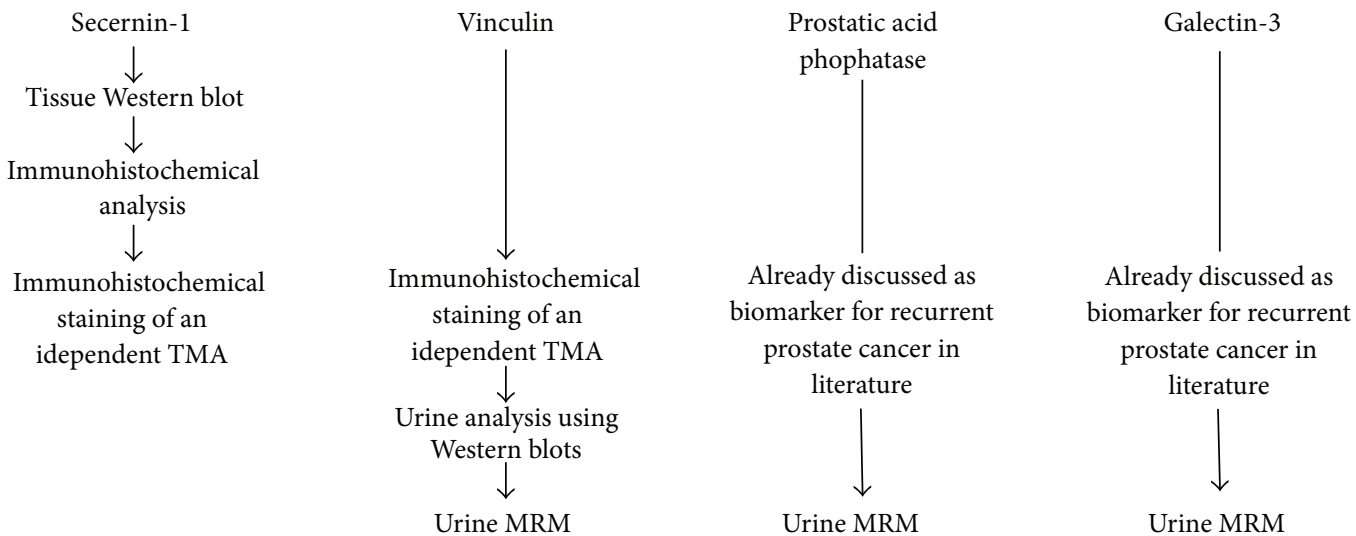

(b)

FIGURE 1: Study design and workflow of prostate cancer biomarker candidate identification (a) and validation (b). (a) Prostate cancer tissue from patients with and without recurrence as well as tumor-free tissue was analyzed using two-dimensional differences in gel electrophoresis (2D-DIGE) and mass spectrometry (MS). (b) Identified potential new biomarker candidates were validated using Western blots, immunohistochemistry, tissue microarrays (TMA), and multiple reaction monitoring (MRM).

grade, and Gleason score were used for both tumor patient groups (with versus without relapse). Only patients without hormonal therapy prior to prostatectomy were included in the study. Samples were obtained from patients treated at the Departments of Urology at the University Hospitals Dresden and Aachen between 1998 and 2010. The study was approved by the local ethics committee (ethics approval Aachen: EK 206/09 and ethics approval Dresden: EK194092004 and EK195092004). Written informed consent was obtained for all specimens. Samples were snap-frozen in liquid nitrogen, and the classification of tumors was done by pathologists in accordance with the UICC TNM System [45].

For details see Table 1. Due to sample limitations, Western blot validation could not always be performed with the identical sample set. Details are listed in Supplementary Table 2 available online at http://dx.doi.org/10.1155/2014/454256.
Validation of potential prostate cancer biomarker candidates by immunohistochemical analysis was done with samples obtained from the Department of Urology in Dresden. Samples were formalin-fixed and paraffin-embedded at the Department of Urology in Dresden. Detailed patient information is listed in Supplementary Table 3.

For validation of an independent sample set, tissue microarrays (TMA) were obtained from the Institute of Pathology, University Hospital Bonn. The study was approved by the Institutional Review Board (IRB) at the University Hospital Bonn, and the IRB waived the need for written informed consent of the participants. Patients underwent surgery between 2004 and 2007 at the University Hospital Bonn and TMA preparation was done as previously described $[46,47]$. Detailed patient information is listed in Supplementary Table 4 and Supplementary Table 5. 
TABLE 1: Sample sets used in the experiments.

\begin{tabular}{|c|c|c|c|c|}
\hline \multirow[b]{2}{*}{ Experiment } & \multicolumn{4}{|c|}{ Sample set } \\
\hline & $\begin{array}{c}\text { Frozen tissue (obtained from } \\
\text { University Hospitals } \\
\text { Dresden and Aachen) }\end{array}$ & $\begin{array}{l}\text { FFPE tissue (obtained } \\
\text { from University Hospital } \\
\text { Dresden) }\end{array}$ & $\begin{array}{c}\text { TMA (obtained from } \\
\text { University Hospital } \\
\text { Bonn) }\end{array}$ & $\begin{array}{l}\text { Urine samples (obtained } \\
\text { from University Hospital } \\
\text { Aachen) }\end{array}$ \\
\hline \multicolumn{5}{|l|}{ IDENTIFICATON } \\
\hline $\begin{array}{l}\text { 2D-DIGE } \\
\text { and MS-analysis }\end{array}$ & $\mathrm{X}$ & & & \\
\hline \multicolumn{5}{|l|}{ VALIDATION (TISSUE) } \\
\hline Western blot secernin-1 & $\mathrm{X}$ & & & \\
\hline IH secernin-1 & & $\mathrm{X}$ & & \\
\hline TMA secernin-1 & & & $\mathrm{X}$ & \\
\hline TMA vinculin & & & $\mathrm{X}$ & \\
\hline \multicolumn{5}{|l|}{ VALIDATION (URINE) } \\
\hline Western blot vinculin & & & & $\mathrm{X}$ \\
\hline MRM vinculin & & & & $\mathrm{X}$ \\
\hline MRM PAP & & & & $\mathrm{X}$ \\
\hline MRM galectin-3 & & & & $\mathrm{X}$ \\
\hline
\end{tabular}

Samples for Western blot analysis of vinculin in urine were obtained from the University Hospital Aachen. Detailed patient information is listed in Supplementary Table 6.

For the MRM-MS analysis, urine samples from the University Hospital Aachen were used (ethics approval Aachen: EK 206/09). Urine samples were obtained between 2005 and 2010 from patients treated at the Department of Urology, University Hospital Aachen. Samples were snap-frozen in liquid nitrogen and stored at $-80^{\circ} \mathrm{C}$ at the Institute of Pathology, University Hospital Aachen, until use. Only samples from patients without neoadjuvant therapy were included in this study. Detailed information is listed in Supplementary Table 7.

Detailed information which sample set was used for which experiment is listed in Table 1.

2.1.2. Manual Microdissection and Tissue Preparation for 2DDIGE and Western Blot Analysis. All tissue samples were stored at $-80^{\circ} \mathrm{C}$ prior to protein isolation. Proteins for $2 \mathrm{D}$ DIGE analysis were isolated from $4 \mathrm{~mm}^{2}$ of a $14 \mu \mathrm{m}$ thin cryoconserved section with a minimum of $80 \%$ of prostatic glands. TissueTec from the embedding and freezing process was removed using $70 \%$ ethanol. The sample sections were stained in a series of ultrapure water, haematoxylin, ultrapure water, and 70\% ethanol. All liquids were used with Complete Protease Inhibitor Cocktail Tablets (Roche, Mannheim, Germany). The areas of interest were marked using the PALM Axiovert 200M (Carl Zeiss Microscopy, Göttingen, Germany) laser and were manually microdissected. Proteins were dissolved in $10 \mu \mathrm{L}$ lysis buffer $(30 \mathrm{mM}$ Tris- $\mathrm{HCl}, 2 \mathrm{M}$ thiourea, $7 \mathrm{M}$ urea, $4 \%$ (w/v) CHAPS; $\mathrm{pH} 8.0$ ). The extracts were sonicated on ice and centrifuged at $4^{\circ} \mathrm{C}$ for $15 \mathrm{~min}$ and $16,000 \times$ g. Supernatants were stored at $-80^{\circ} \mathrm{C}$.

2.1.3. Protein Labeling and Two-Dimensional Difference in Gel Electrophoresis (2D-DIGE). Protein lysates were labeled with $2 \mathrm{mM}$ Cy5 dye using the GE CyDye DIGE Fluor Labeling
Kit (GE Healthcare, UK) according to the manufacturer's instructions. As an internal standard, proteins from all patient samples were pooled and $5 \mu$ g were labeled with $2 \mathrm{mM}$ Cy3 dye. Labeled samples were combined. Rehydration buffer (7 mM urea, $2 \mathrm{M}$ thiourea, 2\% (w/v) CHAPS, 1\% DTT, 1\% IPG buffer $\mathrm{pH}$ 3-11 NL (GE Healthcare, UK), 0.002\% bromphenol blue) was added to give a total volume of $450 \mu \mathrm{L}$. Rehydration, isoelectric focusing and gel electrophoresis were performed as described by Labbus et al. [48].

2.1.4. Gel Image Analysis. 2D-DIGE gels were visualized using a Typhoon 9410 fluorescence scanner (GE Healthcare) with excitation/emission at 554/575 nm (Cy3) and $648 / 663 \mathrm{~nm}$ (Cy5). Scanning resolution was 100 microns and the photomultiplier tube was set to $550 \mathrm{~V}$. Gel image and statistical analyses were done using the Delta2D 4.0 Software (Decodon, Greifswald, Germany). The Delta2D data set was first normalized by dividing each spot volume by the sum of all spot volumes on the respective gel image. By opening the analysis tool of Delta2D logarithmic function is performed automatically; furthermore data is standardized (resulting in means of zero and standard deviations of one). The recommended workflow includes fusing all images and detecting the spots on the resulting fused image, which contains all spots of the original images. The spot pattern is then transferred to all original images. Therefore, in this approach, no missing values appear. Additionally detailed Delta2D workflow information is described by Berth et al. [49]. Spots showing a quantitative difference of a $\geq 1.5$-fold change between nontumor and tumor groups and between the two tumor groups (i.e., with or versus without a relapse), respectively, were included in further analyses. Additionally, either a Student's $t$-test (as a parametric test) or a MannWhitney $U$-test (as a nonparametric test) with a $P$ value of $<0.05$ was accepted as statistical relevant. The $U$-test and $t$ test were used because of uncertainty concerning presence of normal distribution ( $t$-test $[50]$; $U$-test $[51,52]$ ). 
2.1.5. Protein Identification Using MALDI-TOF MS/MS and $L C-M S / M S$. Trypsin digestion and protein identification using MALDI-TOF MS and MS/MS were done as previously described [48]. All 2D-DIGE protein spots that were not identified using MALDI-TOF MS were further analyzed using LC-MS/MS as follows. Trypsin-digested proteins were extracted from the gel spot using $10-20 \mu \mathrm{L}$ extraction solution $(0.1 \%$ TFA/Acetonitrile $1: 1)$ and sonicated on ice for $15 \mathrm{~min}$. The supernatant containing the extracted peptides was transferred to a new glass tube. For a second extraction step, the gel spot was once more incubated and sonicated with $10-20 \mu \mathrm{L}$ extraction solution for $15 \mathrm{~min}$. The supernatants were combined and remaining acetonitrile was removed in a vacuum Speedvac concentrator 5301 (Eppendorf, Germany). Peptides were diluted with $0.1 \%$ TFA to a final volume of $17 \mu \mathrm{L}$. Peptide concentration was determined by amino acid analysis as described elsewhere [53]. Mass spectrometric analysis was done using a LTQ Orbitrap Velos (Thermo Scientific, San Jose, USA) online, coupled to an Ultimate 3000 RSLCnano system (Dionex, Idstein, Germany). Samples were preconcentrated on a trap column (Acclaim PepMap 100, $300 \mu \mathrm{m} \times 5 \mathrm{~mm}, \mathrm{C} 18,5 \mu \mathrm{m}$, and $100 \AA$ ) and separated on an Acclaim PepMap 100, $75 \mu \mathrm{m} \times 25 \mathrm{~cm}, \mathrm{C} 18,3 \mu \mathrm{m}$, and $100 \AA$ analytical column. The flow rate was $0.4 \mu \mathrm{L} / \mathrm{min}$ with a linear gradient of $4-35 \%$ buffer B (84\% acetonitrile and $0.1 \%$ formic acid) for $65 \mathrm{~min}$. MS-analyses were done in FT-master scan mode. The collision energy was $35 \mathrm{eV}$ with an activation time of 10 seconds. The intensity counts for MS/MS were set to 500 counts with a dynamic exclusion time of 35 seconds. Five most intense precursor ions were selected for fractionation in a data-dependent acquisition approach (TOP5). Columns were washed after each sample. Protein identification was achieved using Proteome Discoverer 1.3 (Version 1.3.0.399; Thermo Scientific, Bremen) with Mascot database (Version 2.3) as search engine and UniprotKB/Swiss-ProtDatabase (Uniprot/Swissprot-Release 2012_02; 534.695 entries) with the following search criteria: protease trypsin, one missed cleavage, $400-10,000 \mathrm{~m} / z, 1.5$ signal-to-noise threshold, mass tolerance of $5 \mathrm{ppm}$, and a fragment and precursor mass tolerance of $0.4 \mathrm{Da}$. FDR (false discovery rate) were calculated using the proteome discoverer application's decoy database search feature (Reference: Xcalibur Proteome Discoverer Version 1.1 User Guide XCALI-97276 Revision A October 2009, http://sjsupport.thermofinnigan.com/TechPubs/manuals/Discoverer_UG.pdf), and the FDR was set to a threshold of 0.01. A decoy approach was used for identification. The used protein inference algorithm was used as stated in the Mascot Manual (http://www.matrixscience.com/help/ interpretation_help.html\#GROUPING): First, Mascot takes the protein with the highest protein score and calls this hit number 1 . Then it takes all other proteins that share the same set of peptide matches or a subset and includes these in the same hit. In the report, they are listed as same-set and subset proteins. With these proteins removed from the list, Mascot now takes the remaining protein with the highest score and repeats the process until all the significant peptide matches are accounted for (Mascot Manual, http://www.matrixscience.com/help/interpretation_help.html\#GROUPING, paragraph "Protein inference"). Protein identification relied on proteins and unique peptides. For more sensitive analysis, an LTQ Velos Pro (Thermo Scientific, San Jose, USA) was used. The instrument was online coupled to an Ultimate 3000 RSLCnano System (Dionex, Idstein, Germany) equipped with an Acclaim PepMap RSLC, $75 \mu \mathrm{m} \times 25 \mathrm{~cm}, \mathrm{C} 18,2 \mu \mathrm{m}$, and $100 \AA$ column. All LC and analysis methods remained constant between the two MS platforms.

Ten proteins (Supplementary Table 12 and Supplementary Table 13) were identified using the Maxis 4G (Bruker Daltonik, Bremen, Germany) controlled by Compass 1.3 for micrOTOF-SR1 Software (Bruker Daltonik, Bremen, Germany). The MS instrument was online coupled to an U3000 LC system (Dionex, Idstein, Germany), controlled by Chromeleon 6.8 SR8, and equipped with a $25 \mathrm{~cm}$ long $\mathrm{C} 18$ analytical column (ID $75 \mu \mathrm{m}$ ) heated up to $50^{\circ} \mathrm{C}$. Thirty $\mu \mathrm{L}$ of each sample in $0.1 \%$ trifluoroacetic acid was injected and analyzed at a flow rate of $350 \mathrm{~nL} / \mathrm{min}$ with a linear gradient of 5 to $40 \%$ acetonitrile achieved through dilution with buffer B (84\% acetonitrile and $0.1 \%$ formic acid). Capillary voltage was 4800 and flow of dry gas was $4 \mathrm{~L} / \mathrm{min}$. Protein identification was performed using ProteinScape 2.0 (Bruker Daltonic, Bremen, Germany) with Mascot (Version 2.3) as search engine and UniprotKB/Swiss-Prot Database (Uniprot/Swissprot-Release 2012_02; 534.695 entries) with the following search criteria: protease trypsin and one missed cleavage, and variable methionine oxidation was allowed. The mass tolerance was $15 \mathrm{ppm}$ for peptides and $0.1 \mathrm{Da}$ for MS/MS identification. FDR and protein inference were calculated as described above.

2.1.6. Ingenuity Pathway Analysis. Ingenuity pathway analysis (IPA, QIAGEN Redwood City, http://www.qiagen.com/ ingenuity) was used to determine Top Diseases, Biofunctions, and Localization of the identified proteins. Direct and indirect relationships were included in the analysis. Molecules and relationships were considered as long as the species was human and molecules and the relationships were experimentally observed. The number of molecules for type, localization, molecular, and cellular functions, as well as the role of the identified proteins in development and function of the physiological systems, were counted.

2.1.7. Protein Selection for Further Validation. Based on IPA and-more importantly-on literature review we selected four proteins for further validation using Western blot analysis, immunohistochemical analysis, and/or MRM analysis. For study design, see Figure 1.

2.1.8. Bradford-Assay. Unless otherwise specified, protein concentrations were determined using the Bio-Rad Bradford assay (Bio-Rad Laboratories, Hercules/California, USA). Forty $\mu \mathrm{L}$ of ultrapure water was mixed with $10 \mu \mathrm{L}$ Bradford reagent and $1 \mu \mathrm{L}$ protein sample. Forty $\mu \mathrm{L}$ ultrapure water mixed with $10 \mu \mathrm{L}$ Bradford reagent was used as a blank. Samples were measured with an ELISA Reader Infinite M200 (Tecan, Männedorf, Switzerland) at an extinction of $595 \mathrm{~nm}$. Protein concentrations were determined by comparing the absorption at $595 \mathrm{~nm}$ with dilution series consisting of $10 \mu \mathrm{L}$ Bradford reagent and $1 \mu \mathrm{g}, 2 \mu \mathrm{g}, 3 \mu \mathrm{g}, 4 \mu \mathrm{g}$, or $5 \mu \mathrm{g}$ of bovine 
TABLE 2: Antibodies used for Western blot analysis.

\begin{tabular}{lccc}
\hline Antibody & Host & Type & Company \\
\hline$\beta$-Actin (A5441) & Mouse & Monoclonal & Sigma Aldrich, St. Louis, USA \\
Secernin-1 & Rabbit & Polyclonal & Sigma Aldrich, St. Louis, USA \\
Vinculin & Mouse & Monoclonal & Fitzgerald, North Acton, USA \\
Anti-mouse + HRP (P0447) & Goat & Polyclonal & DAKO, Hamburg, Germany \\
Anti-rabbit + HRP (P0448) & Goat & Polyclonal & DAKO, Hamburg, Germany \\
Peroxidase anti-Mouse IgG (PI-2000) & Horse & Polyclonal & Vector Laboratories, USA \\
Peroxidase anti-Rabbit IgG (PI-1000) & Goat & Polyclonal & Vector Laboratories, USA \\
\hline
\end{tabular}

TABle 3: Antibodies used for immunohistochemistry.

\begin{tabular}{|c|c|c|c|c|c|c|}
\hline Target protein & Species & Type & Company & Dilution & $\begin{array}{l}\text { Incubation time and } \\
\text { temperature }\end{array}$ & Positive control \\
\hline Secernin-1 & Rabbit & Polyclonal & $\begin{array}{l}\text { Sigma Aldrich, St. } \\
\text { Louis, USA }\end{array}$ & $1: 1000$ & $1 \mathrm{~h}, 37^{\circ} \mathrm{C}$ & Testis \\
\hline Vinculin & Mouse & Monoclonal & $\begin{array}{l}\text { Fitzgerald, North } \\
\text { Acton, USA }\end{array}$ & $1: 1000$ & Overnight, $4^{\circ} \mathrm{C}$ & Testis \\
\hline
\end{tabular}

serum albumin (BSA), respectively, filled up to $40 \mu \mathrm{L}$ ultrapure water.

2.1.9. Western Blot. Ten $\mu$ g protein samples were mixed $1: 4$ $(\mathrm{v}: \mathrm{v})$ with SDS sample buffer (4\% SDS, $0.5 \mathrm{M}$ Tris- $\mathrm{HCl}$ pH 6.8, 40\% glycerol, $10 \% \beta$-mercaptoethanol, and $0.002 \%$ bromophenol blue). Samples were incubated for $5 \mathrm{~min}$ at $95^{\circ} \mathrm{C}$ and loaded onto a Novex NuPAGE $4-12 \%$ Bis-Tris gel (Invitrogen, Carlsbad, CA, USA). After electrophoresis at $130 \mathrm{~V}$ until the bromophenol blue front reached the end of the gel, proteins were electrotransferred onto polyvinylidene fluoride membranes (Millipore Corporation, Bedford, MA, USA). Blots were blocked with $10 \%$ milk powder in TBS$\mathrm{T}(0.5 \mathrm{M} \mathrm{NaCl}, 1 \mathrm{M}$ tris $\mathrm{pH} 7.5,0.5 \%$ tween $)$. Antibodies used for immunodetection of desired proteins are listed in Table 2. For visualization, the membrane was incubated with SuperSignal West Femto Maximum Sensitivity Substrate (Thermo Scientific, Rockford, IL, USA) and exposed to Amersham Hyperfilm (GE Healthcare). Densitometric analyses of the results were performed using ImageJ 1.45 (Oracle Corporation, National Institute of Health, USA).

2.1.10. Immunohistochemistry. For immunohistochemistry, FFPE tissues were dewaxed 3 times with xylene (15 min each), 2 times with $100 \%$ ethanol (10 min each), 2 times with $96 \%$ ethanol ( $5 \mathrm{~min}$ each) and $70 \%$ ethanol (5 min each), and 3 times with ultrapure water ( $5 \mathrm{~min}$ each). For antigen retrieval, slides were incubated in $20 \%$ citrate buffer $\mathrm{pH} 6.0$ for $30 \mathrm{~min}$ in a $98^{\circ} \mathrm{C}$ water bath and then cooled for $30 \mathrm{~min}$ and washed 5 times with phosphate buffered saline (PBS). Blocking of endogen peroxidase was done with $3 \% \mathrm{H}_{2} \mathrm{O}_{2}$ for $15 \mathrm{~min}$. Slides were washed 5 times with PBS prior to blocking of unspecific antibody binding with DAKO protein block serum-free (Dako, Hamburg, Germany) for $20 \mathrm{~min}$ at $37^{\circ} \mathrm{C}$. Primary antibodies were diluted in $1 \%$ milk powder in PBS. The incubation conditions are listed in Table 3.

Slides were washed with PBS and incubated at $37^{\circ} \mathrm{C}$ with DAKO Envision premade biotin-free enhancer solution (for detection of mouse and rabbit primary antibodies) for $3 \mathrm{~min}$ and then were washed and incubated in PBS for one hour. A DAKO Liquid DAB Substrate Chromogen System Kit (DAKO) was used for development: $1 \mathrm{~mL}$ buffer was mixed with $20 \mu \mathrm{L}$ DAB. Slides were incubated with this solution for 5 to $10 \mathrm{~min}$ and then were washed with ultrapure water and incubated in PBS for $5 \mathrm{~min}$. Incubation in hematoxylin for 10 min was used for counterstaining. Slides were incubated in tap water for $10 \mathrm{~min}$ and dehydrated once in $70 \%$ ethanol for $1 \mathrm{~min}$, once in $96 \%$ ethanol for $1 \mathrm{~min}$, twice in $100 \%$ ethanol for $2 \mathrm{~min}$, and twice in xylene for $5 \mathrm{~min}$. The stained tissue samples were mounted with vitroclud (R. Langenbrinck, Germany) and glass cover slides in case the Remmele score were used for scoring of immunohistochemical stainings. Scoring was done as described elsewhere [54] whereby the described scoring of nuclear staining was adapted to the cytoplasmatic staining (adapted Remmele score).

\subsection{Analysis of Urine Samples}

2.2.1. Preparation of Urine Samples for Vinculin Western Blot Analysis. Urine proteins were precipitated with 10 volumes of ice cold methanol. Samples were incubated for $30 \mathrm{~min}$ at $-20^{\circ} \mathrm{C}$ followed by centrifugation at $16,000 \times \mathrm{g}$ at $4^{\circ} \mathrm{C}$ for $20 \mathrm{~min}$. The supernatant was discarded and the sediment was dried at room temperature. Proteins were suspended in $10 \mu \mathrm{L}$ lysis buffer (30 mM Tris- $\mathrm{HCl}, 2 \mathrm{M}$ thiourea, $7 \mathrm{M}$ urea, and $4 \%$ (w/v) CHAPS; pH 8.0).

2.2.2. Preparation of Urine Samples for MRM-MS Analysis. A total of 23 urine samples from the University Hospital Aachen were used for MRM analysis. All samples were prepared as follows: $2 \mathrm{~mL}$ urine, corresponding to $160 \mu \mathrm{g}$ of protein, was centrifuged at $3,900 \times \mathrm{g}$ for $30 \mathrm{~min}$ at $4^{\circ} \mathrm{C}$ to remove cells and cell debris. Each supernatant was transferred to a Millipore Amicon Ultra-4 centrifugal filter unit (10,000 MWCO (molecular weight cutoff)) and centrifuged at 3,900 $\times \mathrm{g}$ until concentrated 4 -fold. The concentrated protein solution was 
washed on filter with $4 \mathrm{~mL} 20 \%$ acetonitrile and $25 \mathrm{mM}$ ammonium bicarbonate and centrifuged at 3,900 $\times \mathrm{g}$ until the volume was reduced to $500 \mu \mathrm{L}$. In a second washing step, the protein solution was diluted with $2 \mathrm{~mL}$ of $25 \mathrm{mM}$ ammonium bicarbonate and centrifuged at 3,900 $\times \mathrm{g}$ until the volume was reduced to $100 \mu \mathrm{L}$. A $18.75 \mu \mathrm{L}$ sample was removed and denatured with $81.25 \mu \mathrm{L}$ of $8 \mathrm{M}$ Urea containing $0.1 \mathrm{M}$ ammonium bicarbonate.

Trypsin digestion was based on the protocol by Selevsek et al. [55]. Briefly, $100 \mu \mathrm{L}$ of the concentrated and denatured protein solution was reduced with $1.2 \mathrm{M}$ DTT (final concentration of $12 \mathrm{mM}$ ) for $30 \mathrm{~min}$ at $37^{\circ} \mathrm{C}$. Proteins were alkylated with $0.5 \mathrm{M}$ iodoacetamide (final concentration of $40 \mathrm{mM}$ ) and incubated for $30 \mathrm{~min}$ at $37^{\circ} \mathrm{C}$. The samples were diluted with $0.1 \mathrm{M}$ ammonium bicarbonate (Sigma-Aldrich, USA) to a final urea-concentration below $2 \mathrm{M}$. The proteins were then digested with Worthington TPCK trypsin $(0.9 \mathrm{mg}$ trypsin in $1 \mathrm{~mL} 10 \mathrm{mM} \mathrm{CaCl}_{2}$-dihydrate containing $25 \mathrm{mM}$ ammonium bicarbonate) at a $20: 1$ (protein to enzyme) ratio and incubated at $37^{\circ} \mathrm{C}$ overnight.

2.2.3. Development of the MRM Assay. The development of an MRM assay involves several stages, the first being the selection of the target peptides that will represent each target protein. The selection rules for these peptides has been discussed in several previous papers [42] and will not be repeated here. Briefly, peptide selection involves optimizing the peptide mass spectrometric detectability by taking into account factors such as the peptide length, the absence of oxidizable residues, and other factors such as the avoidance of residue combinations such as RK and KK, which can lead to missed cleavages. These are avoided because they could lead to a reduction in sensitivity by multiple isoforms of the target peptides. The efficiency of tryptic digestion $<95 \%$ was verified with ExPASy Peptide-Cutter (http://web .expasy.org/peptide_cutter/). If all of the above criteria were met, peptides were ranked based on their previous detection using both The GPM (http://gpmdb.thegpm.org/index.html) and Peptide Atlas (https://db.systemsbiology.net/sbeams/cgi/ PeptideAtlas/Search) databases. All of the SIS-peptides used in this study are listed in Supplementary Table 8.

2.2.4. Synthesis and Purification of Isotopically Labeled Standard Peptides. Synthesis and purification of SIS-peptides were done as previously described [43].

\subsubsection{MRM Q1/Q3 Ion Pair Selection Using Direct Infusion} (Peptide Optimization). Prior to MRM analysis, the ion pairs (called "transitions") for protein quantification had to be selected. This "peptide optimization" was done as previously described [43], with the following changes: the nebulizer gas flow was $60 \mathrm{psi}$ and the scanning time was $500 \mathrm{~ms}$. A list of all possible $b$ - and $y$-ion series for $2+$ and $3+$ precursor ion charge spanning a range of $\mathrm{m} / \mathrm{z}$ from 200 to 1100 was generated using the Agilent MassHunter Optimizer For Peptides Software (Version B.05.00, Agilent). Product ions within $1 \mathrm{Da}$ were excluded to ensure that only a single targeted product-ion was measured. All +2 or greater product ions were eliminated from the method using Mathew Monroe's Molecular Weight Calculator Freeware (http://www.alchemistmatt.com/). For each peptide the top 5 transitions, defined as those transitions with the most abundant signals, were selected for chemical interference screening.

2.2.6. Interference Screening of SIS-Peptides in Urine Samples. Interference testing has been described elsewhere for plasma [43], and a similar process is followed for urine. Basically, interference testing requires examining the ratios of each endogenous and SIS-peptide's transitions in buffer and in urine. If there are no interferences, the ratio in buffer and in urine should be the same.

A pooled urine sample from 5 female and 5 male donors collected from first void, midstream, and with sodium azide added to a produce a final concentration of $0.05 \%$ (Bioreclamation LLC, Westbury NY, USA; Lot No BRH683580), was used as the matrix for the interference testing.

Urine samples were prepared for tryptic digestion as described above. $100 \mathrm{fmol} / \mu \mathrm{L}$ of each measured SIS-peptide was added to tryptic-digested urine and the samples were desalted on a Waters Positive Pressure Manifold using Waters Oasis 96-well $\mu$ Elution Plates $30 \mu \mathrm{g}$ HLBa sorbent (batch number 115B) according to the manufacturer's instructions. Briefly, $\mu$ Elution plates were activated with $200 \mu \mathrm{L}$ of $100 \%$ methanol and equilibrated with $200 \mu \mathrm{L} 0.15 \%$ formic acid. Samples were diluted 1:1 with formic acid before adding them to sorbent. The sorbent was washed twice with $200 \mu \mathrm{L}$ $0.1 \%$ formic acid prior to elution with $100 \mu \mathrm{L}$ of $50 \%$ acetonitrile $/ 0.1 \%$ formic acid. After a short centrifugation step, samples were frozen at $-80^{\circ} \mathrm{C}$ and lyophilized overnight. Before LC/MRM-MS analysis, samples were rehydrated in $0.1 \%$ formic acid (mobile phase A). Both urine digest and matrix-free samples were analyzed in triplicate.

All LC/MRM-MS measurements were carried out on an Agilent 1290 infinity UHPLC system coupled to an Agilent 6490 triple quadruple mass spectrometer (Agilent Technologies, Santa Clara, CA, USA) with MassHunter Workstation Software (Agilent, B.04.01). Twenty $\mu \mathrm{L}$ of each sample was injected and separated at a flow rate of $400 \mu \mathrm{L} / \mathrm{min}$ on an Agilent Zorbax RRHD Eclipse Plus C18, 2.1 × $150 \mathrm{~mm}$ and $1.8 \mu \mathrm{m}$ analytical column using a mobile phase gradient from 3 to $90 \%$ phase B (90\% acetonitrile/ $0.1 \%$ formic acid) in a $43 \mathrm{~min}$ analysis. The gradient was as follows: $0 \mathrm{~min}, 3 \% \mathrm{~B} ; 1,5 \mathrm{~min}$, $7 \% \mathrm{~B} ; 16$ min 15\% B; $18 \mathrm{~min}, 15,3 \% \mathrm{~B} ; 33 \mathrm{~min}, 25 \% \mathrm{~B} ; 38 \mathrm{~min}$, $45 \% \mathrm{~B} ; 29 \mathrm{~min}, 90 \% \mathrm{~B} ; 43 \mathrm{~min}, 3 \% \mathrm{~B}$. All acquisition methods used have previously described acquisition parameters [43] and scheduled retention times with a minimum dwell time of $20 \mathrm{~ms}$ to allow for the maximum number of peptides to be analyzed per injection.

The most intense interference-free signal producing transition was later used for peptide quantification (the quantifier) while other two transitions were used for quality control (the qualifiers). All quantifier and qualifier transitions are listed in Supplementary Table 8.

2.2.7. Concentration Balancing of SIS-Peptides in Urine Samples. For the highest quantitation accuracy, the concentration 
of each SIS-peptide should match as closely as possible to the concentration in the sample [56]. Abundance of each SISpeptide should be at least between $1 \times 10^{3}$ and $1 \times 10^{4}$ to ensure optimal peak shape and therefore correct integration. The difference in peak areas between the natural and SIS peaks should be no more than a factor of 10 for optimal quantitation. Supplementary Table 9 shows the final SISpeptide concentrations.

2.2.8. MRM-Based Quantitation of Vinculin, Galectin-3, and Prostatic Acid Phosphatase in Urine and MRM Data Analysis. Urine samples for scheduled MRM analysis were prepared as described above. Concentration-balanced SIS-peptides were spiked in (Supplementary Table 9) and the samples were desalted and lyophilized and then reconstituted in $20 \mu \mathrm{L} 0.1 \%$ formic acid prior to analysis as described in Interference Screening of SIS-Peptides in Urine Samples section.

MRM data was processed and evaluated with Agilent's MassHunter Quantitative Analysis Software (Agilent B.04.00) and Agilent's Integrator Algorithm for Peak Integration. All peaks were verified for correct chromatographic peak selection and integration. The ratio between the natural peptide peak area and SIS-peptide's peak area was calculated as the response ratio (RR). Natural peptide concentrations were calculated by multiplication of the RR by the concentration of the SIS-peptides that had been spiked into the sample. The accuracy of the calculation was further increased by verifying the purity of the SIS-peptides by amino acid analysis (AAA) and capillary zone electrophoresis (CZE); data are listed in Supplementary Table 9.

2.2.9. Statistical Evaluation. Statistical analyses for Western blot analysis, immunohistochemical analysis, and MRM analysis were done using SPSS 15.0 (SPSS, Chicago, IL). P values of $<0.05$ were defined as statistically significant. Twosided Mann-Whitney $U$-test was used to detect differences in abundance levels among the various groups studied, based on the Western blot, immunohistochemical, and MRM-MS results.

\section{Results}

3.1. Identification of Novel Potential Biomarkers for Prostate Cancer in Tissue Using 2D-DIGE with MS Identification. For the identification of differentially regulated proteins in prostate cancer, 12 prostatectomy samples from prostate cancer patients without biochemical relapse, 11 prostatectomy samples from patients with biochemical relapse, and 14 corresponding tumor-free prostate cancer tissue samples were comparatively analyzed by $2 \mathrm{D}$-DIGE saturation labeling. Comparison of all samples revealed 1000 gel spots common to all gels by using the Delta2D software. Tumor and tumor-free samples as well as tumor samples from patients with and without biochemical relapse could be distinguished from each other using principal component analysis (Figure 2). Comparison of the tumor-free versus the tumor samples revealed 37 protein spots with bigger normalized volume and 27 protein spots with smaller normalized volume in the tumor samples compared to the tumor-free samples (Supplementary Table 10). Of these, 14 protein spots were identified using MALDI-MS and LC-MS/MS (Figure 2, Table 4, and Supplementary Table 12).

In addition, 12 prostatectomy samples from patients without biochemical relapse and 11 prostatectomy samples from patients with biochemical relapse were compared to reveal proteins involved in tumor aggressiveness. The analysis resulted in 22 protein spots which showed bigger normalized volumes and 13 protein spots which showed smaller normalized volumes prostatectomy samples of patients with biochemical relapse compared to samples of patients without biochemical relapse (Supplementary Table 11). Of these, 29 deregulated protein spots were identified using MALDIMS and LC-MS-MS (Supplementary Table 13). Among these, prostatic acid phosphatase (PAP), vinculin, secernin-1 (SCRN1), lamin A/C, and gelsolin were identified. All of the identified proteins are listed in Table 5.

\subsection{Ingenuity Pathway Analysis (IPA) of the Identified} Proteins. Ingenuity pathway analysis of the potential new biomarkers identified using 2D-DIGE and MS revealed that most of the deregulated proteins are located in the cytoplasm. As shown Figure 3, 60.0\% of the differentially-expressed proteins in the tumor versus tumor-free sample set, and $53.3 \%$ within the aggressive versus non aggressive tumor sample set, were located in the cytoplasm. Proteins that are differentially expressed between tumor-free tissue and prostate cancer tissue were mostly associated with cellular assembly (5 proteins), cellular development (4 proteins), cell morphology (3 proteins), cellular compromise (i.e., associated with damage or degeneration of cells; 1 protein), and carbohydrate metabolism (1 protein). The differentially expressed proteins in tumors with or without relapse were mostly associated with cellular growth and proliferation (12 proteins), cellular development (10 proteins), cellular movement (8 proteins), cell morphology (5 proteins), and carbohydrate metabolism (2 proteins). Detailed results, as well as the classification of the identified proteins and their functions in development and in the physiological system, are shown in Table 6 and Figure 3.

\subsection{Validation of Potential Tissue Biomarker Candidates} Found by DIGE. Some candidates found by 2D-DIGE and MS (secernin-1, vinculin, prostatic acid phosphatase (PAP), and galectin-3) were selected for further validation. Two of those, PAP and galectin-3, have already been suggested as potential biomarkers for prostate cancer. Secernin-1 2DDIGE analysis also revealed that secernin-1 shows significantly lower abundance in recurrent prostate cancer tumors compared to prostate cancer tumors without biochemical relapse. For Western blot validation, eight tumor-free tissue samples and four prostatectomy samples from patients without and six prostatectomy samples from patients with relapse were analyzed (Figure 4). Secernin-1 showed a significant downregulation in tumors $(P=0.001)$ but no deregulation between tumors with and without relapse $(P=0.762)$. Further immunohistochemical analysis of the 13 prostatectomy samples from prostate cancer patients without relapse, the 14 samples from patients with relapse, and the 43 tumor free tissue samples (kindly provided by the University Hospital 
TABLE 4: Deregulated proteins in prostate cancer identified with 2D-DIGE and MS.

\begin{tabular}{|c|c|c|c|c|c|c|}
\hline Spot & & Acc. no. & Protein name & Ratio Tf versus Tu & $\begin{array}{c}P \text { value }(t \text {-test }) \mathrm{Tf} \\
\text { versus Tu }\end{array}$ & $\begin{array}{c}P \text { value }(U \text {-test }) \mathrm{Tf} \\
\text { versus Tu }\end{array}$ \\
\hline Down 01 & & P22626 & $\begin{array}{l}\text { Heterogeneous nuclear } \\
\text { ribonucleoproteins A2/B1 }\end{array}$ & -21.8 & 0.043 & 0.035 \\
\hline Down 05 & & P17661 & Desmin & -15.7 & 0.156 & 0.024 \\
\hline Down 06 & & P17661 & Desmin & -9.1 & 0.085 & 0.009 \\
\hline Down 04 & & P17661 & Desmin & -3.8 & 0.037 & 0.012 \\
\hline Down 09 & & P09493 & Tropomyosin alpha-1 chain & -2.9 & 0.035 & 0.042 \\
\hline Down 10 & & P09493 & Tropomyosin alpha-1 chain & -2.9 & 0.009 & 0.020 \\
\hline Down 08 & & P09493 & Tropomyosin alpha-1 chain & -2.8 & 0.010 & 0.019 \\
\hline Down 07 & & P12277 & Creatine kinase B-type & -2.7 & 0.045 & 0.009 \\
\hline Down 11 & & Q05682 & Caldesmon & -2.2 & 0.115 & 0.026 \\
\hline Down 02 & & P08670 & Vimentin & -1.7 & 0.053 & 0.024 \\
\hline Down 03 & & P17661 & Desmin & -1.6 & 0.039 & 0.110 \\
\hline Up 01 & & COEA1 & $\begin{array}{l}\text { Collagen alpha-1(XIV) } \\
\text { chain }\end{array}$ & 2.4 & 0.104 & 0.042 \\
\hline \multirow[t]{3}{*}{ Up 03} & Mix & ANXA5 & Annexin A5 & 3.7 & 0.038 & 0.033 \\
\hline & & A1BG & Alpha-1B-glycoprotein & 3.7 & 0.038 & 0.033 \\
\hline & & P04217 & Alpha-1B-glycoprotein & 3.7 & 0.038 & 0.033 \\
\hline Up 02 & & TCPA & $\begin{array}{l}\text { T-complex protein } 1 \\
\text { subunit alpha }\end{array}$ & 46.7 & 0.405 & 0.049 \\
\hline
\end{tabular}

2D-DIGE: two-dimensional differences in gel electrophoresis; MS: mass spectrometry; Acc. no.: accession number; Tf: tumor free; Tu: tumor; $U$-test: two-sided Mann-Whitney $U$-test; ratio: division of the mean; mean: normalized spot volume.

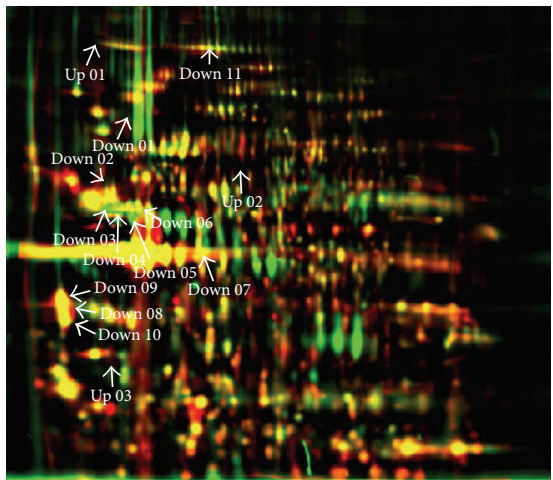

(a)

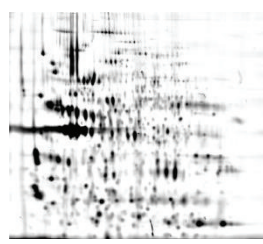

(b)

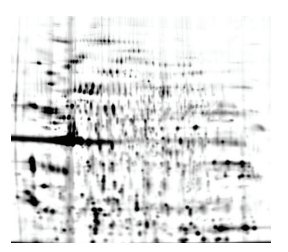

(c)

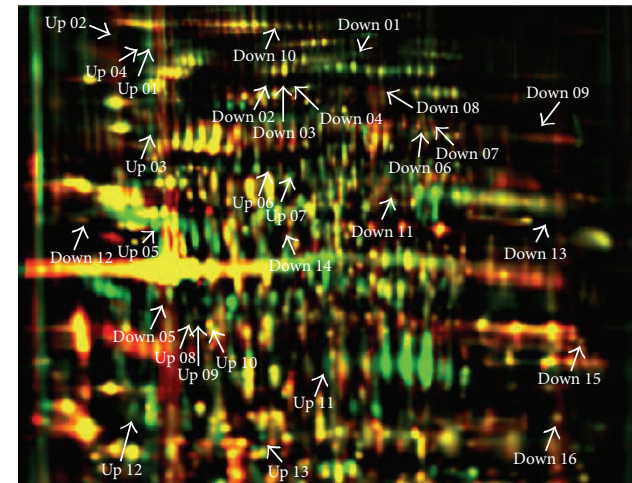

(d)

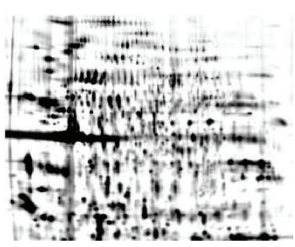

(e)

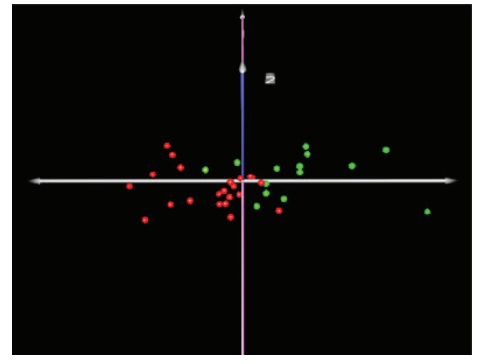

$(\mathrm{g})$

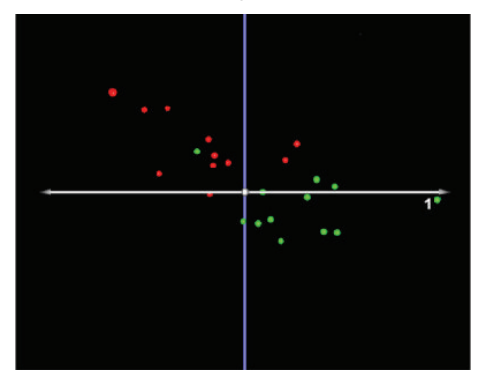

(h)

FIGURE 2: 2D-DIGE analysis of 14 tumor free prostate tissue samples, 12 prostatectomy samples from prostate cancer patients without relapse in a 5-year followup, and 11 prostatectomy samples from patients with relapse. (a) Overlay of 2D-DIGE gels of prostatectomy samples from tumor-free tissue areas ((b), green) and patients with prostate cancer ((c), red). (d) Overlay of 2D-DIGE gels from prostatectomy samples from patients without ((e), red) and with ((f), green) relapse. Downregulated spots in prostate cancer and prostate cancer with relapse, respectively, are annotated with "down." Upregulated spots in these samples are annotated with "up." Principal component analysis (PCA) of prostate cancer (red) and tumor-free tissue (green) (g) and prostate cancer samples without (red) and with relapse (green) (h). 
TABLE 5: Deregulated proteins in recurrent prostate cancer identified with 2D-DIGE and MS.

\begin{tabular}{|c|c|c|c|c|c|c|}
\hline Spot & & Acc. no. & Protein name & $\begin{array}{c}\text { Ratio } \\
+ \text { versus }- \text { rec }\end{array}$ & $\begin{array}{l}P \text { value }(t \text {-test }) \\
+ \text { versus }- \text { rec }\end{array}$ & $\begin{array}{c}P \text { value }(U \text {-test }) \\
+ \text { versus }- \text { rec }\end{array}$ \\
\hline Down 13 & & P01857 & Ig gamma-1 chain $\mathrm{C}$ region & -274.3 & 0.334 & 0.041 \\
\hline Down 01 & & FLNA & Filamin-A & -12.0 & 0.269 & 0.031 \\
\hline Down 12 & & SCRN1 & Secernin-1 & -8.9 & 0.088 & 0.044 \\
\hline Down 04 & & O95394 & $\begin{array}{l}\text { Phosphoacetylglucosamine } \\
\text { mutase }\end{array}$ & -7.5 & 0.228 & 0.012 \\
\hline Down 08 & & PYGB & $\begin{array}{l}\text { Glycogen phosphorylase, } \\
\text { brain form }\end{array}$ & -5.6 & 0.176 & 0.031 \\
\hline Down 03 & & P06396 & Gelsolin & -5.3 & 0.092 & 0.023 \\
\hline Down 02 & & P06396 & Gelsolin & -3.5 & 0.109 & 0.019 \\
\hline Down 16 & & LEG3 & Galectin-3 & -3.4 & 0.272 & 0.033 \\
\hline Down 05 & & PTGR2 & Prostaglandin reductase 2 & -3.2 & 0.047 & 1.169 \\
\hline Down 06 & & LMNA & Lamin-A/C & -2.6 & 0.036 & 0.023 \\
\hline Down 14 & & TTC38 & $\begin{array}{l}\text { Tetratricopeptide repeat } \\
\text { protein } 38\end{array}$ & -2.4 & 0.087 & 0.036 \\
\hline \multirow[t]{2}{*}{ Down 15} & Mix & MDHM & $\begin{array}{l}\text { Malate dehydrogenase, } \\
\text { mitochondrial }\end{array}$ & -2.3 & 0.233 & 0.014 \\
\hline & & P51911 & Calponin-1 & -2.3 & 0.233 & 0.014 \\
\hline Down 09 & & P16870 & $\begin{array}{l}\text { Carboxypeptidase E } \\
\text { precursor }\end{array}$ & -2.2 & 0.122 & 0.049 \\
\hline Down 10 & & $\mathrm{CO} 6 \mathrm{~A} 2$ & Collagen alpha-2(VI) chain & -1.9 & 0.018 & 0.031 \\
\hline Down 07 & & LMNA & Lamin-A/C & -1.7 & 0.133 & 0.036 \\
\hline Down 11 & & G6PD & $\begin{array}{l}\text { Glucose-6-phosphate } \\
\text { 1-dehydrogenase }\end{array}$ & -1.7 & 0.255 & 0.036 \\
\hline \multirow[t]{2}{*}{ Up 08} & Mix & Q9UBR2 & Cathepsin $\mathrm{Z}$ precursor & 1.2 & 0.529 & 0.951 \\
\hline & & P20774 & Mimecan precursor & 1.2 & 0.529 & 0.951 \\
\hline Up 10 & & CAZA1 & $\begin{array}{l}\text { F-actin-capping protein } \\
\text { subunit alpha-1 }\end{array}$ & 1.5 & 0.209 & 0.042 \\
\hline Up 05 & & PAPP & Prostatic acid phosphatase & 1.8 & 0.048 & 0.056 \\
\hline Up 01 & & VINC & Vinculin & 2.2 & 0.027 & 0.031 \\
\hline Up 03 & & GRP78 & $\begin{array}{c}78 \mathrm{kDa} \text { glucose-regulated } \\
\text { protein }\end{array}$ & 2.5 & 0.025 & 0.036 \\
\hline Up 02 & & COEA1 & $\begin{array}{c}\text { Collagen alpha-1(XIV) } \\
\text { chain }\end{array}$ & 2.5 & 0.075 & 0.049 \\
\hline Up 09 & & KCD12 & $\begin{array}{c}\mathrm{BTB} / \mathrm{POZ} \\
\text { domain-containing protein } \\
\text { KCTD12 }\end{array}$ & 2.6 & 0.158 & 0.045 \\
\hline Up 11 & & GLO2 & $\begin{array}{l}\text { Hydroxyacylglutathione } \\
\text { hydrolase, mitochondrial }\end{array}$ & 3.2 & 0.047 & 0.042 \\
\hline \multirow[t]{2}{*}{ Up 12} & Mix & ANXA5 & Annexin A5 & 3.2 & 0.032 & 0.074 \\
\hline & & A1BG & Alpha-1B-glycoprotein & 3.2 & 0.032 & 0.074 \\
\hline Up 04 & & SYNEM & Synemin & 4.9 & 0.055 & 0.027 \\
\hline Up 13 & & PRDX4 & Peroxiredoxin-4 & 4.9 & 0.022 & 0.004 \\
\hline Up 06 & & ANXA4 & Annexin A4 & 6.4 & 0.288 & 0.042 \\
\hline Up 07 & & TCPA & $\begin{array}{l}\text { T-complex protein } 1 \\
\text { subunit alpha }\end{array}$ & 51.9 & 0.275 & 0.031 \\
\hline
\end{tabular}

2D-DIGE: two-dimensional differences in gel electrophoresis; MS: mass spectrometry; Acc. no.: accession number; + rec: prostate cancer with recurrence; rec: prostate cancer without recurrence; $U$-Test: two-sided Mann-Whitney $U$-Test; ratio: division of the mean; mean: normalized spot volume. 


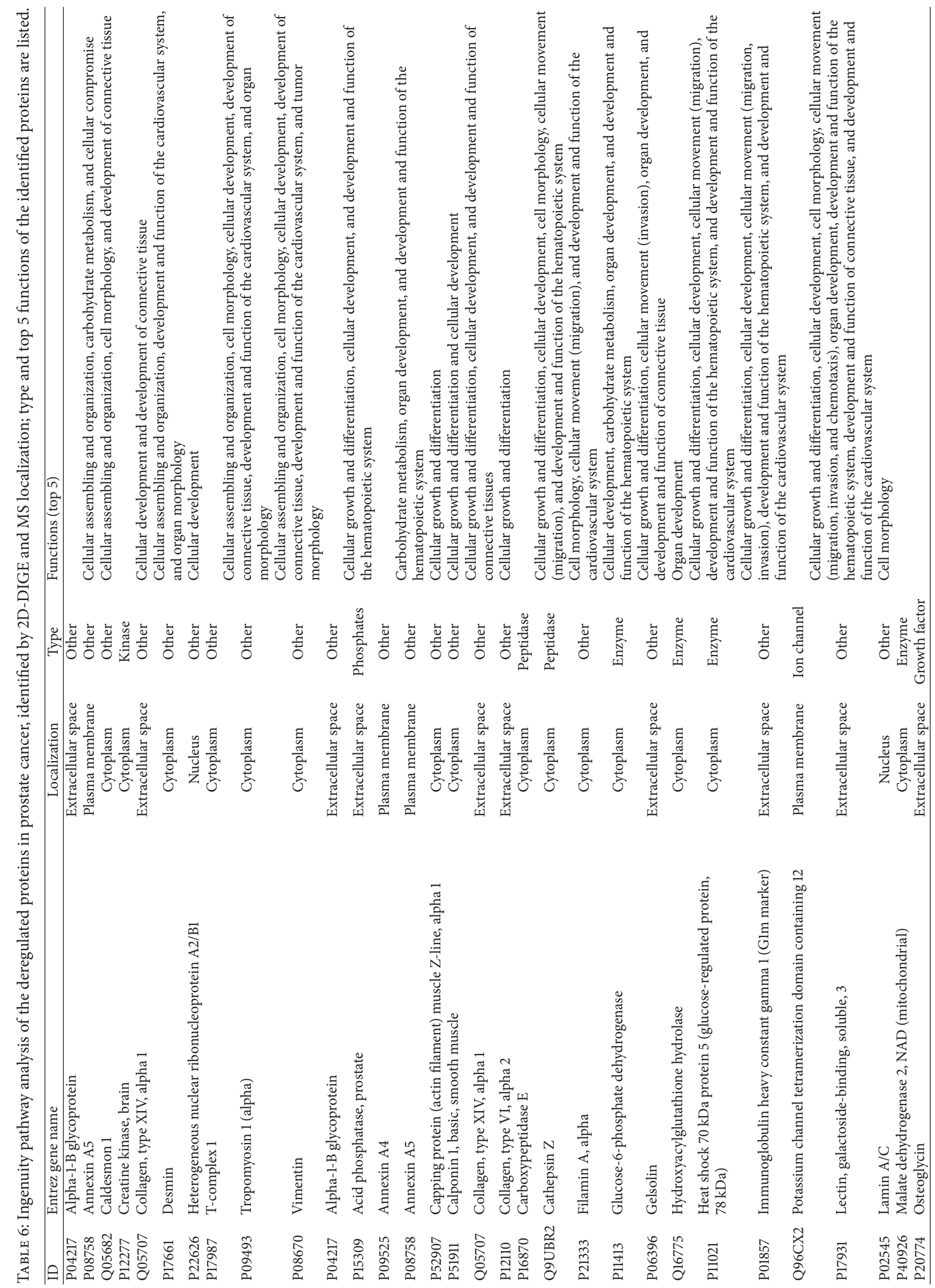




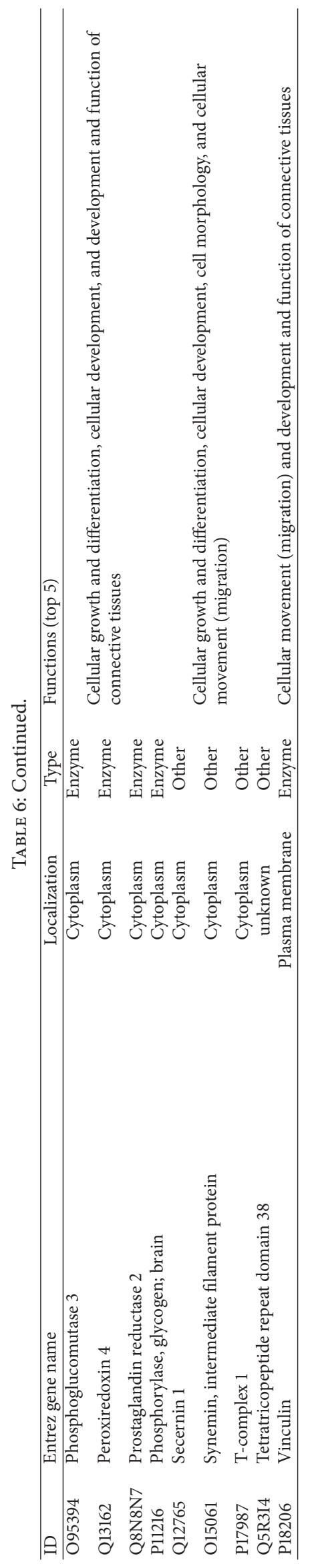




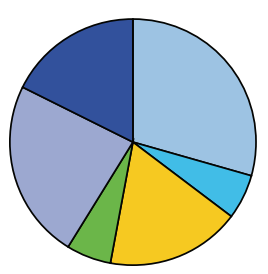

$\square$ Cellular assembly

$\square$ Cellular compromise

$\square$ Cell morphology

Carbohydrate metabolism

$\square$ Cellular development

$\square$ Others

(a)

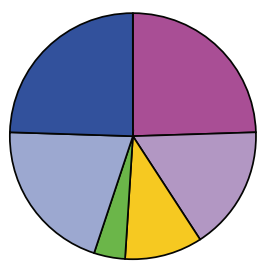

- Cellular growth and proliferation

$\square$ Cellular development

$\square$ Cell morphology

Cellular movement

$\square$ Carbohydrate metabolism

$\square$ Others

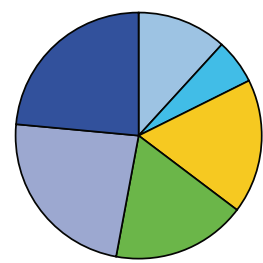

ㅁ Organ morphology

Tumor morphology

$\square$ Connective tissue

development and function

口 Cardiovascular system

development and function

$\square$ Tissue development

$\square$ Others

(c)

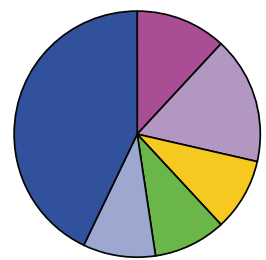

口 Organ development

Hematological system development and function

$\square$ Connective tissue development and function

$\square$ Tissue development

口 Cardiovascular system

development and function

a Others

(b)

(d)
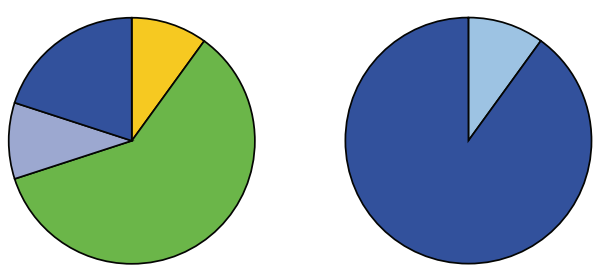

$\square$ Nucleus

口 Cytoplasm

口 Plasma membrane

- Extracellular space (e)

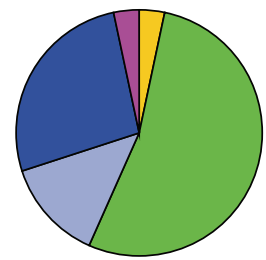

$\square$ Nucleus

당oplasm

Plasma membrane

口 Extracellular space

u Unknown $\square$ Kinase

- Others (f)

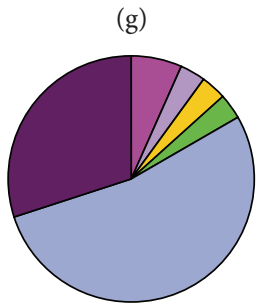

- Peptidase

Phophatase

$\checkmark$ Ion channel

Growth factor

$\square$ Others

- Enzyme

FIGURE 3: Ingenuity pathway analysis of the proteins that were deregulated between tumor-free samples and prostate cancer samples ((a), (c), (e), and (g)) as well as proteins that were deregulated between prostate cancer samples from patients with and without relapse ((b), (d), (f), and (h)). Distribution of molecular and cellular functions ((a) and (b)), role of the identified proteins in development and function of the physiological systems ((c) and (d)), localisation ((e) and (f)), and type of the identified proteins ((g) and (h)) are shown.

Dresden) validated the results of the Western blot: tumors from patients with and without relapse showed a significantly lower immunohistochemical score (median 1.0 for tumor tissue) than tumor-free tissue (mean 3.00; $P<0.001$; Supplementary Figure 1). Differences in expression levels between tumors with and without relapse could not be shown. Moreover, immunohistochemical staining showed secernin-1 expression in the basal cell layer but not in the luminal cells itself. To further examine the potential use of secernin-1 as a potential biomarker candidate for prostate cancer, and to discriminate between prostate cancer and prostatitis, five tissues with prostatitis were analyzed. In these experiments, the areas with prostatitis showed no difference in secernin-1 expression levels compared to the noninflamed, tumor-free tissue areas (Figures 5(i)-5(k)). These results were further validated with immunohistochemical staining of an independent tissue microarray (TMA) of prostate cancer patients kindly provided by University Hospital Bonn. To test for secernin-1 expression, 124 tumor free samples, 49 intraepithelial neoplasia lesions (PIN), 52 patients without biochemical relapse, and 16 patients with biochemical relapse were analyzed. The results of this TMA showed the same regulation of secernin-1 as the previous immunohistochemical analysis: tumor-free tissues showed significantly higher secernin-1 expression than tumors $(P<0.001)$, but no difference was found between patients with and without relapse (Figures 5(a)-5(h)). Immunohistochemical secernin1 staining could detect prostate cancer with a sensitivity of $98.0 \%$ and a specificity of $99.2 \%$ for a threshold score of $\geq 1$ versus $<1$. For a more precise scoring, an adapted Remmele score was used to classify the secernin-1 expression, and the results are shown in Figures 5(a)-5(h) and Supplementary Table 14. The PIN showed higher secernin-1 expression levels than the tumors but lower secernin-1 expression than the tumor-free tissues $(P<0.01)$.

Vinculin. Because secernin-1 is downregulated in prostate cancer, it was considered to be a potential biomarker candidate for the diagnosis of prostate cancer but was not suitable for the early detection of a recurrence.

Vinculin was validated as a potential biomarker candidate for recurrent prostate cancer. Immunohistochemical analysis 

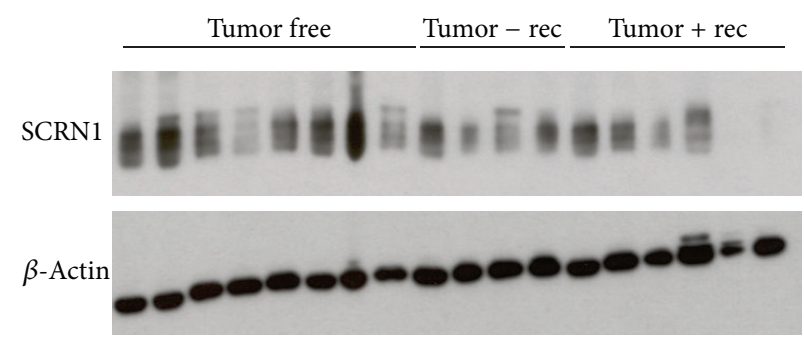

(a)

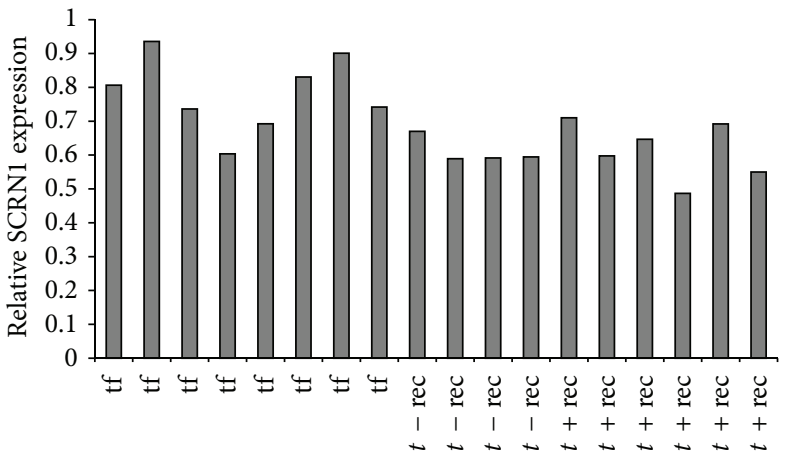

(b)

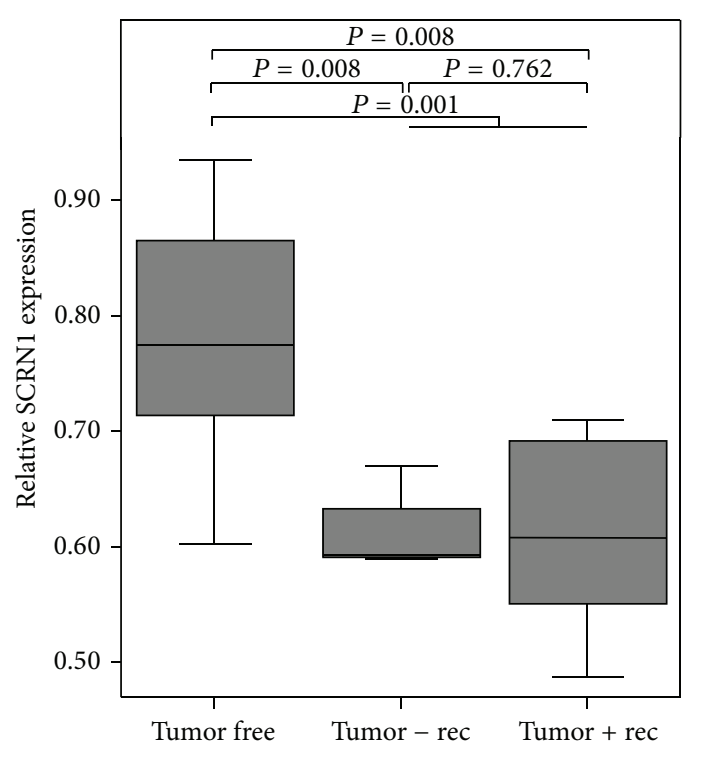

(c)

FIGURE 4: Western blot analysis of secernin-1 (SCRN1) and $\beta$-actin as a house keeping protein in prostate cancer tissue and tumor-free tissue samples. (a) Western blot analysis. (b) Relative SCRN1 expression levels were calculated densitometrically in reference to the $\beta$-actin expression level. (c) Boxplot of the densitometrically determined SCRN1 expression levels. A significant difference between tumors without $(t-\mathrm{rec})$ and with recurrence $(t+\operatorname{Rec})$ is not detectable $(P=0,762)$ but SCRN1 is significantly downregulated in prostate cancer tissue compared to tumor-free tissue samples (tf) $(P=0.001)$.

of the previously described TMA set showed a significant upregulation of vinculin in PIN and prostate cancer compared to tumor-free tissue $(P<0.001$ for tumor-free versus PIN and $P<0.001$ for tumor-free versus prostate cancer patients without relapse and $P=0.013$ for tumor free versus prostate cancer patients with relapse). Immunohistochemical vinculin staining could detect prostate cancer with a sensitivity of $38.0 \%$ and a specificity of $56.9 \%$ for a threshold score $\leq 1$ versus $>1$. Biochemical prostate cancer recurrence could be detected with specificity of $65.5 \%$ and a sensitivity of $50.0 \%$. Detailed scoring information as well as representative examples of immunohistochemical staining are shown in Figure 6 and Supplementary Table 15.

\subsection{Validation of Potential Prostate Cancer Biomarker Candi- dates in Urine}

Vinculin. To validate vinculin as a potential noninvasive biomarker candidate for prostate cancer, we determined the abundance of vinculin in the urine of prostate cancer patients. Urine from 14 control patients without prostate cancer, 33 prostate cancer patients without relapse, and 15 patients with relapse were analyzed using Western blot. Vinculin expression was scored from 0 (no vinculin antibody signal detectable) to 4 (strong vinculin antibody signal detectable). Again, vinculin expression was significantly higher in the urine of prostate cancer patients than in controls $(P=0.006$, Figure 7). Most importantly, vinculin levels in urine from prostate cancer patients with relapse were higher than in urine from patients without relapse (median score without relapse 1.00; median with relapse 1.75; $P=0.229$; median vinculin score in the control urine 0.250; $P=0.006$ ). Moreover, $62.5 \%$ of the patients without relapse showed no vinculin or low vinculin levels (score $0-1$ ) while only $37.5 \%$ of these patients showed high vinculin levels (score 2-4). In contrast, only $40 \%$ of patients with relapse showed low vinculin levels (score $0-1$ ) while $60 \%$ of these patients showed high vinculin levels (score 2-4). Vinculin levels in Western blots of urine $>1$ could detect prostate cancer with a sensitivity of $54.2 \%$ and a specificity of $85.7 \%$. Biochemical prostate cancer recurrence could be detected with specificity of $60.6 \%$ and a sensitivity of $40.0 \%$.

Because Western blot analysis is not practical for daily routinely use in the clinic, we tested the ability of multiple reaction monitoring (MRM) to detect vinculin abundance in urine. In the MRM-MS analysis of vinculin, 16 prostate cancer patients (nine without relapse and seven with relapse) and seven control urine samples were used. Vinculin could be detected in concentrations up to $0.55 \mathrm{pmol} / \mathrm{mg}$ protein in patients' urine. Moreover, vinculin levels were higher in prostate cancer patients' urine (median $0.109 \mathrm{pmol} / \mathrm{mg}$ ) than in the urine of the control group (median $0.090 \mathrm{pmol} / \mathrm{mg}$ ). Notably, the vinculin levels in urine from patients with relapse were higher (median $0.120 \mathrm{pmol} / \mathrm{mg}$ ) than the vinculin levels from patients without relapse (median $0.100 \mathrm{pmol} / \mathrm{mg}$ ) (Figure 7).

3.5. Validation of Additional Proteins as Potential Biomarker Candidates in Urine Using MRM-MS. PAP, Galectin-3, and Secernin-1. Three proteins in our initial 2D-DIGE and MS 


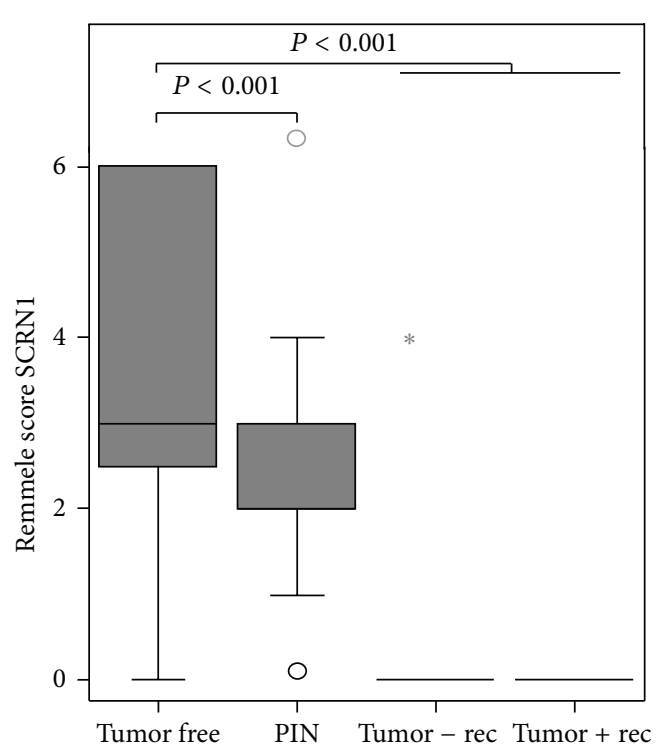

(a)

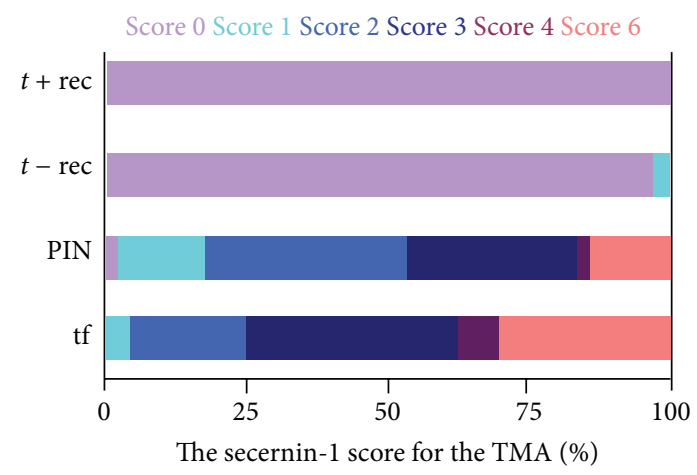

(b)

\begin{tabular}{c|c|c} 
Patient & $\begin{array}{c}\text { Secernin-1 score } \\
\text { in inflammation }\end{array}$ & $\begin{array}{l}\text { Secernin-1 score } \\
\text { in normal glands }\end{array}$ \\
\hline 1 & 2 & 2 \\
2 & 1 & 1 \\
3 & 1 & 1 \\
4 & 3 & 3 \\
5 & 2 & 2
\end{tabular}

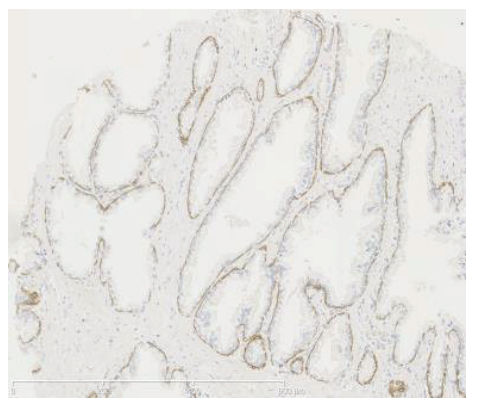

(c)

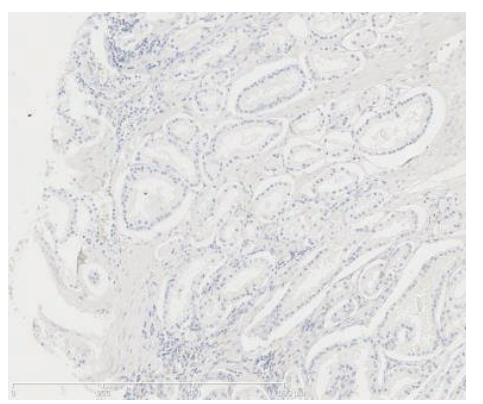

(e)

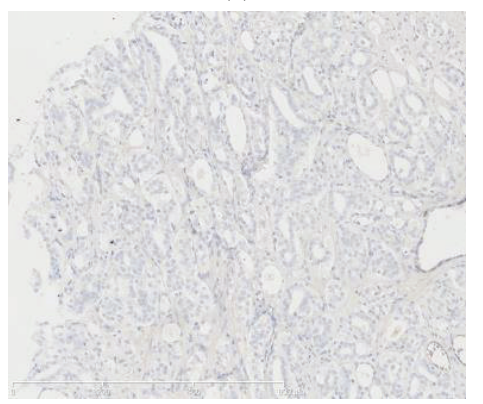

(g)

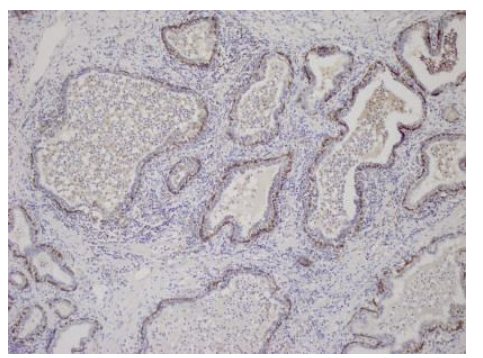

(j)

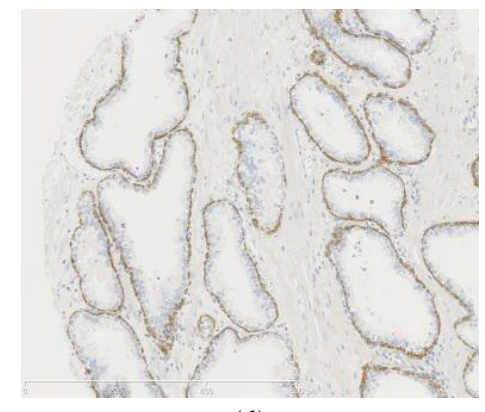

(d)

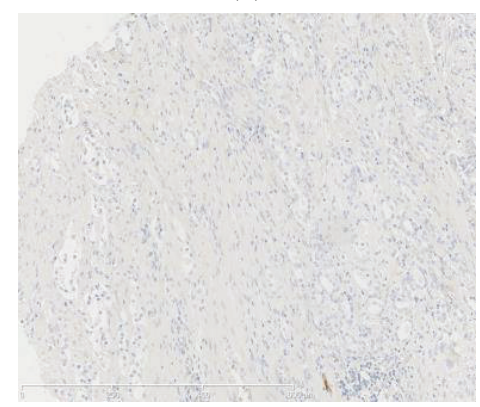

(f)

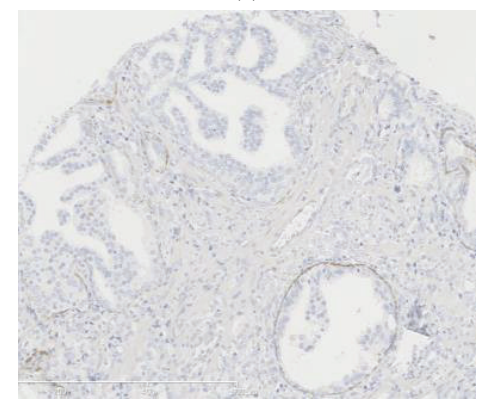

(h)

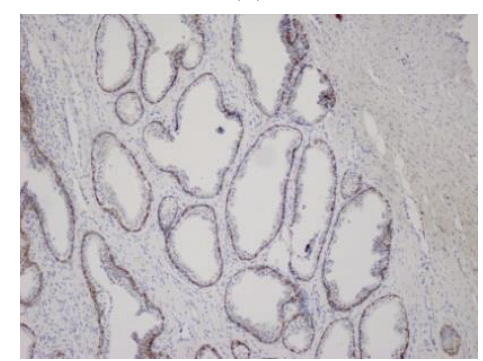

(k)

FIGURE 5: (a)-(h) Representative immunohistochemistry of secernin-1 in an independent tissue microarray (TMA) obtained from the University Hospital Bonn. (a) Boxplot of the secernin-1 expression levels in the analyzed patient groups. (b) Percentages of each score in each analyzed patients group. For more detailed information, an adapted Remmele score was used for classification of the secernin-1 expression. (c) and (d) Tumor-free prostatectomy samples. (e) and (f) Prostatectomy samples of prostate cancer patients without relapse. (g) and (h) Prostatectomy samples of prostate cancer patients with relapse. Secernin-1 expression is significantly downregulated in prostate cancer tissue compared to tumor-free tissue samples $(P<0.001)$. Downregulation of secerin-1 starts in the peri-intraepithelial neoplasia (PIN) as PIN lesions showed less secerin-1 expression than tumor-free tissue samples $(P<0.001)$ but stronger secernin- 1 expression than prostate cancer tissue $(P<0.001)$. (i) $-(\mathrm{k})$ Representative immunohistochemical staining of 5 prostatectomy samples of patients with prostatitis $(\mathrm{j})$ and corresponding normal prostate tissue $(\mathrm{k})$ as well as a table (i) of the results of all 5 analyzed patients obtained from the University hospital Aachen. Secernin-1 staining intensity is not affected by inflammation: the five analyzed tumor-free tissue samples showed the same staining intensity for secernin-1 as the corresponding inflamed tissue. 


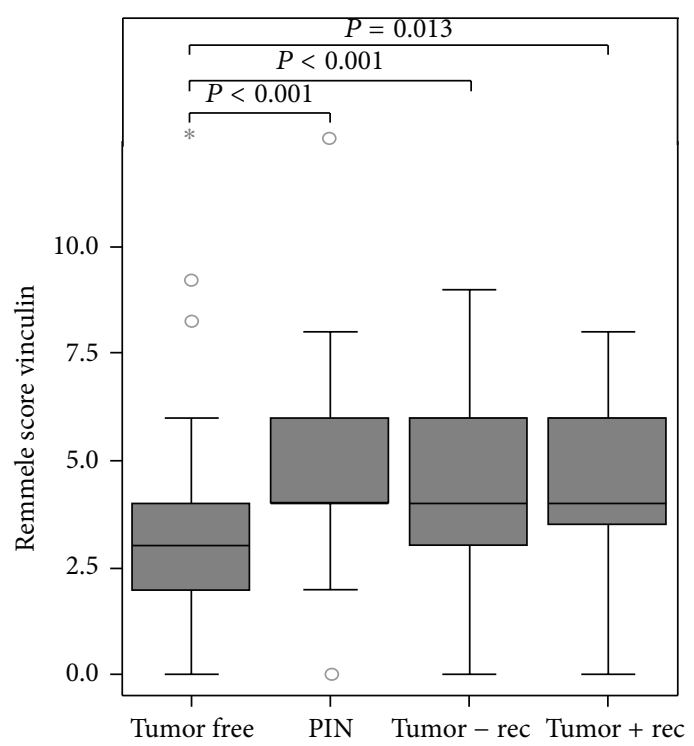

(a)

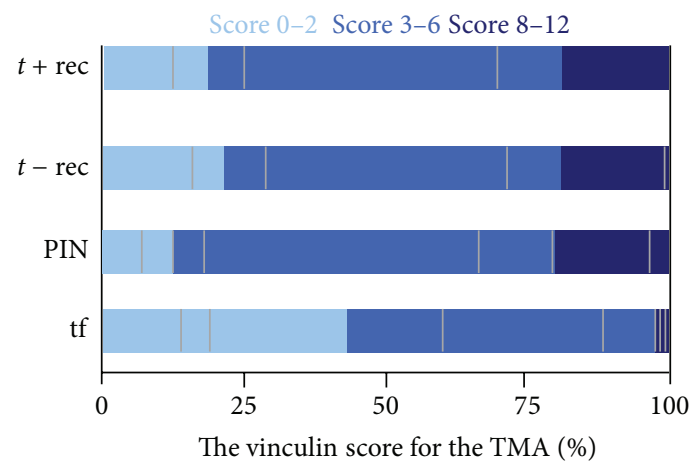

(b)

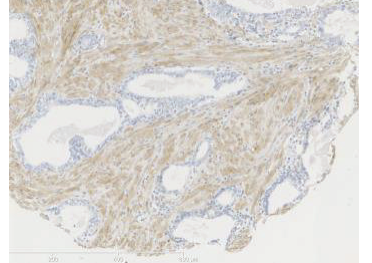

(c)

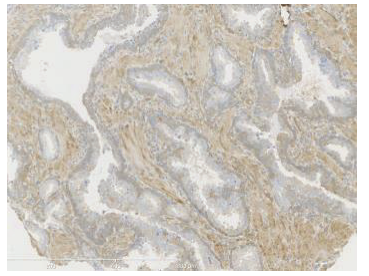

(e)

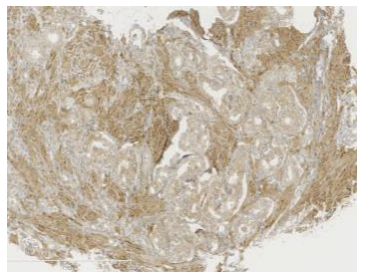

(g)

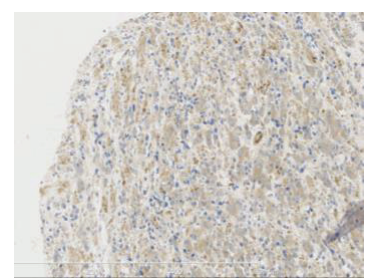

(i)

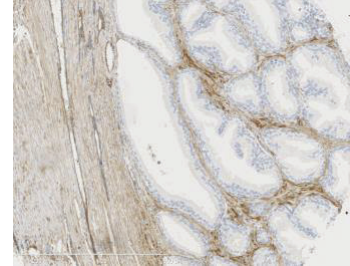

(d)

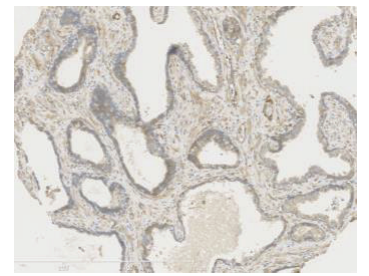

(f)

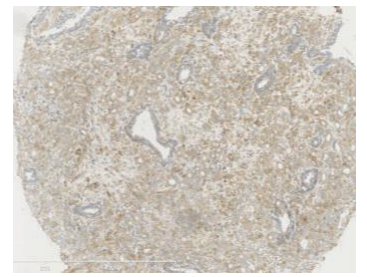

(h)

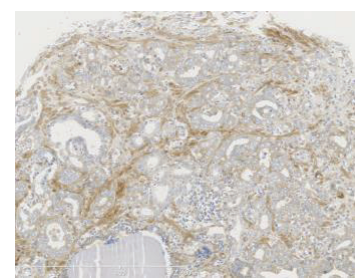

(j)

FIgURE 6: Representative immunohistochemistry of vinculin in an independent tissue microarray (TMA) obtained from the University Hospital Bonn. 116 tumor-free tissue samples, 54 prostatic intraepithelial neoplasia (PIN) lesions, 54 prostatic samples from patients without relapse $(-\mathrm{rec})$, and 16 prostatectomy samples from prostate cancer patients with relapse $(+\mathrm{rec})$ were analyzed. Boxplots of the immunohistological scores of the stained tissue. (b) Percentage of each score in each analyzed patients group. For more detailed information, an adapted Remmele score was used to classify the vinculin expression. (c)-(j) Immunohistochemically stained tissue: (c) and (d) tumorfree prostatectomy samples, (e) and (f) prostatectomy samples of PIN, (g) and (h) prostatectomy samples of prostate cancer patients without relapse, and (i) and (j) prostatectomy samples of prostate cancer patients with relapse. Vinculin is significantly upregulated in periintraepithelial neoplasia (PIN) and prostate cancer compared to tumor-free tissue samples $(P<0.001)$.

experiments were found to be associated with prostate cancer (secernin-1, PAP, and galectin-3) were chosen for a proof of principal MRM-MS study, using urine from nine prostate cancer patients without relapse and seven patients with relapse. Urine samples from seven patients without prostate cancer were used as controls. In MRM-MS results, PAP was found to show higher protein levels in the urine of prostate cancer patients compared to the PAP concentrations in the urine of the control group (median control urine $=1.21 \mathrm{pmol} / \mathrm{mg}$ median prostate-cancer patient urine $=$ $6.26 \mathrm{pmol} / \mathrm{mg} ; P=0.012$, Figure 8$)$. However, no significant difference in PAP concentration in the urine of patients with and without relapse was found. Galectin-3 showed significantly lower protein levels in urine from prostatecancer patients with relapse compared to urine from patients without relapse (median control urine $=0.27 \mathrm{pmol} / \mathrm{mg}$, median in urine of prostate-cancer patients without relapse $=$ $0.48 \mathrm{pmol} / \mathrm{mg}$; median in urine of prostate-cancer patients with relapse $=0.13 \mathrm{pmol} / \mathrm{mg} ; P=0.017$, Figure 8$)$. Secernin-1 was not detected in the patient urine samples.

\section{Discussion}

4.1. Identifying Potential New Biomarker Candidates for Prostate Cancer. Ten potential biomarker candidates for prostate cancer diagnosis and 32 potential prognostic biomarker candidates to discriminate nonrecurrent from recurrent prostate cancer were identified using 2D-DIGE and MS. Ingenuity pathway analysis (IPA) was performed in order to classify the identified proteins. A comparison of tumor and tumorfree tissue revealed ten general prostate cancer biomarker candidates. These ten proteins were differentially regulated 


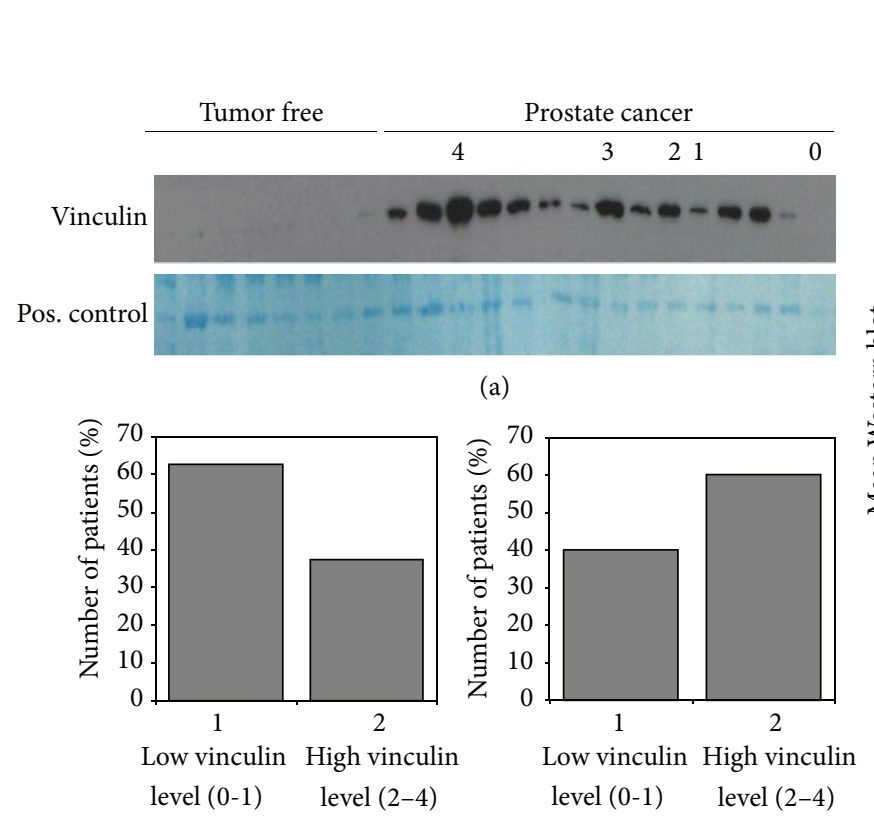

(b)

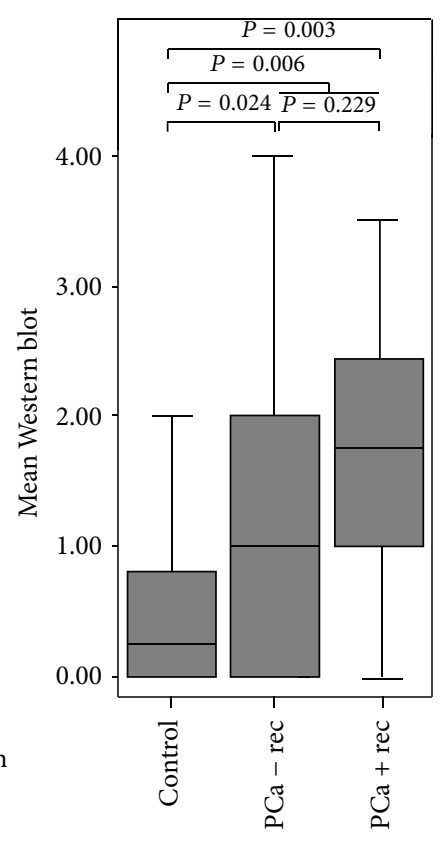

(d)

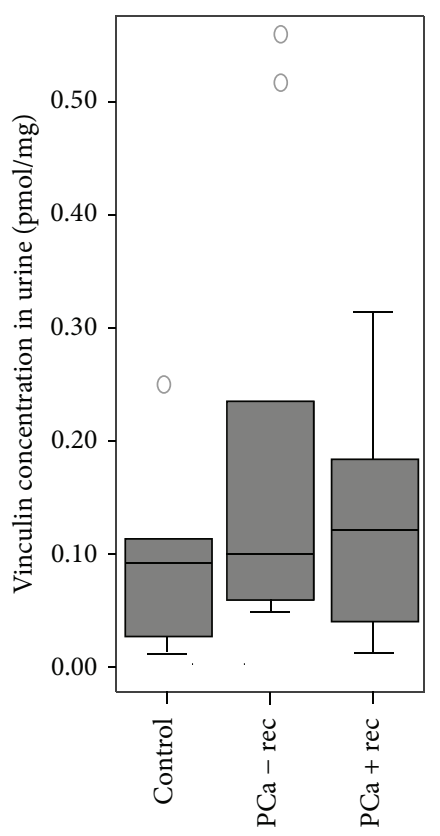

(e)

FIGURE 7: Validation attempts of vinculin levels. (a) Representative Western blot results of the vinculin levels in urine of prostate cancer patients and control patients. Coomassie brilliant blue stained gel as a positive control (pos. control). (b) Percentage of patients without recurrence with high and low vinculin levels in urine. (c) Percentage of patients with recurrence with high and low vinculin levels in urine. (d) Results of all 34 analyzed patients without recurrence, 15 prostate cancer patients with relapse and 12 analyzed control urines: boxplot of the vinculin levels in prostate cancer patients without $(-\mathrm{rec})$ and with recurrence $(+\mathrm{rec})$ compared to control patients. Vinculin shows a tendency to be upregulated in prostate cancer patients with recurrence compared to patients without recurrence $(P=0.229)$. Moreover, vinculin is significantly upregulated in prostate cancer patients compared to control patients $(P=0,006)$. (e) MRM analysis of seven urine samples from control patients without prostate cancer, nine prostate cancer patients without recurrence and seven prostate cancer patients with recurrence. Vinculin (peptide SLGEISALTSK) is upregulated in prostate cancer patients urine compared to the urine of control patients $(P=0.438)$.

between tumor and tumor-free tissue and are mostly associated with cellular assembly, cellular development, cell morphology, cellular compromise, and carbohydrate metabolism. The 32 identified potential biomarker candidates for recurrence in prostate cancer are associated with cellular growth and proliferation, cellular development, cellular movement, cell morphology, and carbohydrate metabolism.

Potential biomarker candidates from both comparisons are associated with cellular development, cell morphology, and carbohydrate metabolism. Cellular assembly and cellular compromise are more associated with general prostate cancer biomarker candidates than with specific biomarker candidates for recurrence. In recurrent prostate cancer, proteins involved in cellular movement, especially invasion and migration, as well as cellular growth and proliferation, are often deregulated. This is in agreement with well-known features of cancer: activating invasion is crucial for the spread of cancer [57], and cellular growth and proliferation are arguably the most fundamental traits of cancer cells [57]. This study showed that cellular movement, particularly invasion and migration, cell growth, and proliferation play a more important role in recurrent prostate cancer than in prostate cancer in general.

The fact that these functions are less associated with general prostate cancer biomarker candidates than with recurrent prostate cancer might reflect the heterogeneity of the disease: as mentioned previously, many prostate cancers are indolent and are not clinically relevant due to very slow proliferation [8]. Therefore, proteins characteristic for proliferation and cellular movement are more especially suitable biomarker candidates for recurrence.

Principal component analysis (PCA) led to the detection of several potential prostate cancer biomarker candidates that have already been discussed as potential prognostic prostate cancer biomarkers in the literature. This underlines the quality of our study. PCA allowed us to detect a clear separation between benign and malignant prostate tissue as well as tissue from recurrent and nonrecurrent prostate cancer in patients. In addition, we also found differential expression levels of PAP and galectin-3, proteins which have already been discussed in literature as potential biomarker candidates for recurrent prostate cancer [58-63].

A. B. Gutman and E. B. Gutman identified increased PAP levels in patients with prostate cancer [64]. Thus, PAP was the first serum biomarker for prostate cancer to be used in clinical practice, although it lacked sufficient sensitivity to be a reliable biomarker for response to systemic therapy or recurrence [65]. Therefore, PAP was replaced by the more sensitive marker PSA. However, there is currently new interest in serum PAP as a possible prognostic marker, particularly 


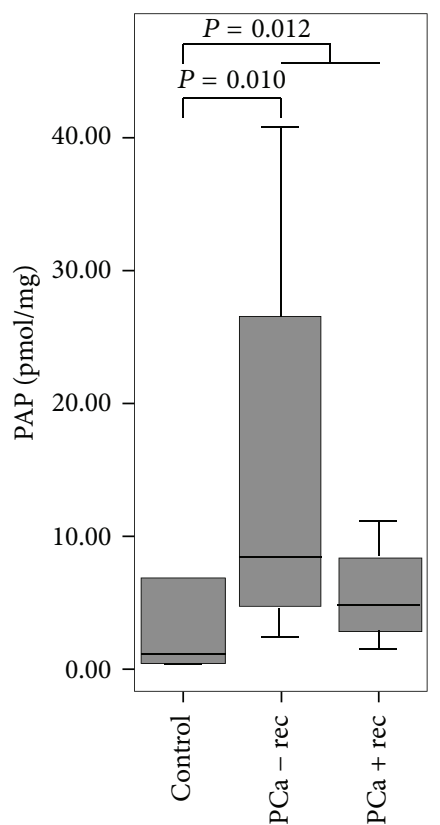

(a)

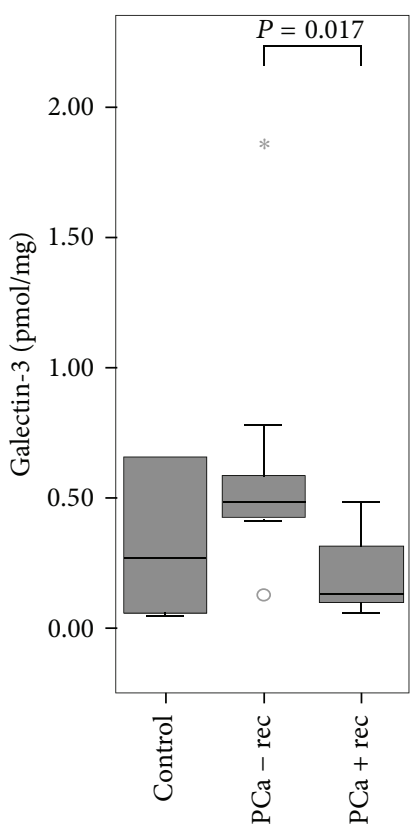

(b)

FIGURE 8: MRM analysis of prostatic acid phosphatase (PAP) peptide FQEELESETLK and galectin-3 peptide IALDFQR in nine urine samples obtained from prostate cancer $(\mathrm{PCa})$ patients without relapse $(-\mathrm{rec})$, seven urine samples from patients with relapse $(+\mathrm{rec})$, and seven samples from control patients. (a) PAP showed significantly higher protein levels in urine of prostate cancer patients compared to control patients urine $(P=0.012)$, while galectin-3 showed significantly lower protein levels in urine of prostate cancer patients with recurrence compared to urine of prostate cancer patients without recurrence $(P=0.017)(b)$.

in the prognosis of intermediate to high-risk prostate cancer $[59,60]$. Fang et al. showed that, in higher-risk prostate cancer, PAP could better predict cancer-specific survival after treatment than PSA concentration and the Gleason score [58]. Surprisingly little is known about PAP as a potential biomarker for prostate cancer in urine. In 1991, Bogdanowicz et al. published a study which compared PAP and PSA levels in urine of prostate cancer patients. They found that PSA and PAP levels increased with each advancing clinical stage. PAP was elevated in $77 \%$ of patients with metastatic cancer [66]. Because we found a higher PAP abundance in recurrent prostate cancer compared to nonrecurrent prostate cancer in our initial 2D-DIGE study of prostate cancer tissue, we used MRM-MS to determine the PAP concentrations in the urine of prostate cancer patients with and without relapse. The detected concentration of PAP was significantly higher in urine of patients with recurrence compared to urine of patients without recurrence and in the control urine. Our results therefore support the hypothesis that PAP might be a good noninvasive prognostic biomarker candidate for prostate cancer. Moreover, PAP might be a noninvasive, urinary biomarker candidate for recurrent prostate cancer. As our patients' cohort was small, however, further analysis is needed to validate PAP as a promising noninvasive, urinary biomarker candidate for recurrent prostate cancer.

The 2D-DIGE experiments revealed galectin-3 as another potential new biomarker candidate for recurrent prostate cancer. Galectin-3 is similar to PAP which is already discussed as a potential biomarker candidate for recurrent prostate cancer in the literature. Galectin-3 levels have been found to be significantly decreased in primary carcinomas and metastatic disease compared to normal and premalignant prostatic tissue [61]. Normal glands show moderate galectin3 expression in the nucleus and cytoplasm. In contrast, galectin-3 is not expressed or its expression is decreased in prostatic cancer cells and it is only present in the cytoplasm $[62,67]$. Moreover, cytoplasmic expression of galectin3 was associated with PSA relapse in univariate analysis [62]. Multivariate analysis revealed galectin-3 as an independent predictor for PSA relapse after the Gleason score and pathological stage [62]. Thus, galectin-3 promotes tumor progression when expressed in the cytoplasm but shows antitumor activity when expressed in the nucleus $[62,68]$. Additionally hormone-refractory tumors showed lower galectin-3 expression than hormone-sensitive tumors [63]. Interestingly, galectin-3 is downregulated in the serum of prostate cancer patients compared to serum of healthy controls [69].

To the best of our knowledge, galectin-3 levels in urine of prostate cancer patients have not yet been studied. The only published data for galectin-3 in urine is a combined assay of galectin-3 methylation specific PCR in combination with GSTP1 (Glutathione S-transferase P1) promoter methylation. In that study, galectin-3 promoter methylation had $100 \%$ specificity and could be detected in 22/22 urine samples of patients [70]. In our study, we analyzed galectin-3 levels in urine of prostate cancer patients using MRM. Consistent with our 2D-DIGE results and other published data, we were able 
to detect galectin-3 downregulation in the urine of prostate cancer patients with recurrence compared to patients without recurrence. Thus, galectin-3 levels in urine are a promising biomarker candidate for the prediction of prostate cancer progression.

2D-DIGE analysis also revealed lower secernin-1 abundance in recurrent prostate cancer compared to nonrecurrent prostate cancer. Validation of secernin-1 expression using tissue Western blots, immunohistochemical staining, and immunohistochemical staining of an independent TMA set showed a significant downregulation of secernin-1 in prostate cancer tissue compared to tumor-free tissue. The downregulation of secernin-1 already starts at the point of PIN. Secernin-1 is described as being deregulated in different carcinomas: secernin-1 is upregulated in colon cancer [71-73], in gastric cancer [73], and in Barrett's esophagus associated with high-grade dysplasia compared to nondysplastic Barrett's esophagus [74]. Moreover, the upregulation of secernin-1 in colorectal cancer compared to normal colorectal tissue correlates with clinicopathological data and is associated with poor prognosis [72]. In contrast to these results, Suehara et al. described secernin-1 as being upregulated in synovial sarcoma with good prognosis compared to synovial sarcoma with poor prognosis [75]. In prostate cancer, Ashida et al. found KIAA0193 (secernin-1) to be downregulated during the transition from PIN to prostate cancer using genomewide gene expression profiling [6]. In summary, secernin1 is up regulated in many tumors, but we and others have demonstrated that secernin-1 is downregulated in prostate cancer tissue compared to tumor-free prostatic tissue. Thus, secernin-1 is a novel potential biomarker candidate for recurrent prostate cancer.

Our immunohistochemical analysis revealed secernin-1 expression in the basal layer, while prostatic luminal cells showed no secernin-1 expression. Notably, some of the tumor glands of the immunohistochemically analyzed tumor sample set in the explorative phase showed a weak secernin1 expression (data not shown). This secernin-1 expression could not be confirmed in the independent TMA obtained from the University Hospital Bonn. Thus, it appears that secernin-1 is mostly expressed in the basal layer and could possibly be lost during the transition from benign prostate tissue to PIN and prostate cancer. As secernin-1 expression is identical in inflamed and normal prostate tissue, secernin1 might be a good biomarker candidate for prostate cancer. Secernin-1 level in urine has not been detected by MRMMS thus far, so the potential of secernin-1 as a noninvasively obtained biomarker candidate in urine from prostate cancer patients is still part of our ongoing work.

Our 2D-DIGE analysis showed that vinculin abundance is higher in recurrent prostate cancer compared to nonrecurrent prostate cancer tissue. Ruiz et al. showed that vinculin is not expressed or only expressed at a very low level in benign prostate hyperplasia. In $92 \%$ of the localized prostate cancer samples, vinculin showed a low expression level. Vinculin showed high expression levels in $16 \%$ of castration-resistant prostate cancer samples and a moderate expression level in $34 \%$ of castration resistant prostate cancer samples [76]. Our TMA analysis also showed that vinculin is significantly upregulated in prostate cancer tissue compared to tumor-free prostatic tissue. This upregulation can already be found in PIN lesions. The Western blot analysis of urine confirmed the significant upregulation of vinculin in prostate cancer patients. Moreover, vinculin showed higher protein levels in the urine of prostate cancer patients with recurrence compared to the urine from patients without recurrence. Thus, future analysis of a larger number of patient samples may validate the potential of vinculin as a biomarker candidate for recurrent prostate cancer. Pang et al. found that vinculin isoform 2 was downregulated in the lymph nodes of metastatic cancer patients compared to lymph node-negative cancer tissues [33]. Thorsen et al. described an alternative splicing variant of vinculin in colon, bladder, and prostate cancer where exon 19 of the vinculin gene is skipped in the cancer tissue, and the long isoform was downregulated in metastatic prostate cancer compared to localized cancer [77]. These two studies showed that different vinculin isoforms may be differentially expressed in prostate cancer. Thus vinculin expression and vinculin isoforms in prostate cancer should be analyzed carefully in the future.

\section{Conclusion}

2D-DIGE combined with MS is a labor-intensive and expensive method with a low throughput of the 2D-DIGE. But the advantages of the proteomic methods compared to DNA methods are magnificent: most functional information about cancer-related genes are placed in the proteome [78] and the discordance of mRNA and protein level elucidates the advantage of proteomic methods $[79,80]$. Moreover, most of FDAapproved diagnostic and prognostic tests for cancer (therapies) are protein-based, which makes it easier to transfer results of protein studies to clinical useful tools than results of genome-based studies [81]. 2D-DIGE enables the separation of thousands of proteins [82], including protein isoforms [32] and posttranslational modifications [83]. Moreover, it has a linear detection rate of $>10.000$ of protein abundances $[39,82]$. Unfortunately, very big or very small proteins, plasma membrane-associated proteins, hydrophobic, very alkaline, or very acidic protein scan not be detected using $2 \mathrm{D}$ DIGE [84]. Moreover, gel-to-gel variability is around $20 \%$. Therefore, 3-5 biological replicates per analyzed group are needed to detect expression differences of a protein from 1.5 to 2 [85]. These disadvantages can be minimized by separating one sample and a standard in each gel [86]. Labelfree proteomic approaches are an alternative to 2D-DIGE for analyzing the proteome. But Megger et al. could show that different proteins can be detected by $2 \mathrm{D}$-DIGE and label-free methods. Therefore, both methods complement to each other [53].

In conclusion, we have successfully demonstrated that 2D-DIGE combined with MS is a powerful tool to identify differentially expressed proteins in prostate cancer tissue. Galectin-3 was verified as a potential prognostic biomarker candidate by analyzing prostate cancer patient urine samples with MRM-MS. MRM-MS was also found to be suitable for quantifying PAP levels in urine. Secernin-1 has been successfully validated as a potential diagnostic biomarker candidate 
for prostate cancer in tissue using Western blot analysis. Vinculin expression has been shown to be upregulated in prostate cancer patient tissue samples, while the urine of recurrent prostate cancer patients showed higher vinculin levels than nonrecurrent prostate cancer patients. Although larger-scale validation studies involving more patients are still needed, vinculin and galectin-3 seem to be promising urinary biomarker candidates for recurrent prostate cancer, while secernin-1 seems to be a useful tissue diagnostic biomarker candidate for prostate cancer.

\section{Conflict of Interests}

The authors declare that they have no conflict of interests regarding the publication of this paper.

\section{Acknowledgments}

The authors would like to thank Kathrin Lüdemann-Franke (Medizinisches Proteom-Center, Ruhr-University Bochum, Germany) for her skillful technical assistance and Dr. Carol Parker (University of Victoria-Genome British Columbia Proteomics Centre, Vancouver Island Technology Park, Victoria, BC, Canada) for proofreading of this paper. The authors thank the FoRUM funding of the Ruhr University Bochum and the START funding of the University Hospital Aachen for financial support. Hanna C. Diehl and Birte Beine and Corinna Henkel were additionally supported by PURE (Protein research Unit Ruhr within Europe). Angela M. Jackson and Christoph H. Borchers are grateful to Genome Canada and Genome BC for support of the University of Victoria-Genome BC Proteomics Centre through funding of the Science and Technology Innovation Centre.

\section{References}

[1] A. Jemal, F. Bray, M. M. Center, J. Ferlay, E. Ward, and D. Forman, "Global cancer statistics," CA Cancer Journal for Clinicians, vol. 61, no. 2, pp. 69-90, 2011.

[2] I. M. Thompson, M. S. Lucia, and C. M. Tangen, "Commentary: the ubiquity of prostate cancer: echoes of the past, implications for the present: 'what has been will be again, what has been done will be done again; there is nothing new under the sun," International Journal of Epidemiology, vol. 36, no. 2, pp. 287-289, 2007.

[3] P. J. Bastian, B. H. Carter, A. Bjartell et al., "Insignificant prostate cancer and active surveillance: from definition to clinical implications," European Urology, vol. 55, no. 6, pp. 1321-1332, 2009.

[4] E. Klein, "Prostate cancer," Urologic Oncology: Seminars and Original Investigations, vol. 26, no. 5, p. 494, 2008.

[5] J. E. McNeal and D. G. Bostwick, "Intraductal dysplasia: a premalignant lesion of the prostate," Human Pathology, vol. 17, no. 1, pp. 64-71, 1986.

[6] S. Ashida, H. Nakagawa, T. Katagiri et al., "Molecular features of the transition from prostatic intraepithelial neoplasia (PIN) to prostate cancer: genome-wide gene-expression profiles of prostate cancers and PINs," Cancer Research, vol. 64, no. 17, pp. 5963-5972, 2004.
[7] R. Montironi, R. Mazzucchelli, A. Lopez-Beltran, M. Scarpelli, and L. Cheng, "Prostatic intraepithelial neoplasia: its morphological and molecular diagnosis and clinical significance," BJU International, vol. 108, no. 9, pp. 1394-1401, 2011.

[8] J.-E. Johansson, O. Andrén, S.-O. Andersson et al., "Natural history of early, localized prostate cancer," The Journal of the American Medical Association, vol. 291, no. 22, pp. 2713-2719, 2004.

[9] M. Han, A. W. Partin, S. Piantadosi, J. I. Epstein, and P. C. Walsh, "Era specific biochemical recurrence-free survival following radical prostatectomy for clinically localized prostate cancer," The Journal of Urology, vol. 166, no. 2, pp. 416-419, 2001.

[10] S. G. Roberts, M. L. Blute, E. J. Bergstralh, J. M. Slezak, and H. Zincke, "PSA doubling time as a predictor of clinical progression after biochemical failure following radical prostatectomy for prostate cancer," Mayo Clinic Proceedings, vol. 76, no. 6, pp. 576-581, 2001.

[11] P. H. Lange, C. J. Ercole, D. J. Lightner, E. E. Fraley, and R. Vessella, "The value of serum prostate specific antigen determinations before and after radical prostatectomy," The Journal of Urology, vol. 141, no. 4, pp. 873-879, 1989.

[12] C. R. Pound, A. W. Partin, M. A. Eisenberger, D. W. Chan, J. D. Pearson, and P. C. Walsh, "Natural history of progression after PSA elevation following radical prostatectomy," Journal of the American Medical Association, vol. 281, no. 17, pp. 1591-1597, 1999.

[13] S. F. Slovin, A. S. Wilton, G. Heller, and H. I. Scher, "Time to detectable metastatic disease in patients with rising prostatespecific antigen values following surgery or radiation therapy," Clinical Cancer Research, vol. 11, no. 24, pp. 8669-8673, 2005.

[14] C.-S. Chen, S.-S. Wang, J.-R. Li et al., "PSA density as a better predictor of prostate cancer than percent-free PSA in a repeat biopsy," Journal of the Chinese Medical Association, vol. 74, no. 12, pp. 552-555, 2011.

[15] C. Y. Hsu, S. Joniau, R. Oyen, T. Roskams, and H. van Poppel, "Detection of clinical unilateral T3a prostate cancerby digital rectal examination or transrectal ultrasonography?" BJU International, vol. 98, no. 5, pp. 982-985, 2006.

[16] T. A. Stamey, M. Caldwell, J. E. McNeal, R. Nolley, M. Hemenez, and J. Downs, "The prostate specific antigen era in the United States is over for prostate cancer: what happened in the last 20 years?" Journal of Urology, vol. 172, no. 4, part 1, pp. 1297-1301, 2004.

[17] C. H. Bangma, M. J. Roobol, and E. W. Steyerberg, "Predictive models in diagnosing indolent cancer," Cancer, vol. 115, supplement 13, pp. 3100-3106, 2009.

[18] G. Guazzoni, M. Lazzeri, L. Nava et al., "Preoperative prostatespecific antigen isoform p2PSA and its derivatives, \%p2PSA and prostate health index, predict pathologic outcomes in patients undergoing radical prostatectomy for prostate cancer," European Urology, vol. 61, no. 3, pp. 455-466, 2011.

[19] A. I. Hinev, V. I. Hadjiev, and N. H. Kolev, "Validation of preoperative nomograms predicting lymph node involvement in prostate cancer: a bi-institutional study," European Urology, vol. 60, no. 6, pp. 1310-1311, 2011.

[20] G. L. Andriole, E. D. Crawford, R. L. Grubb III et al., "Mortality results from a randomized prostate-cancer screening trial," The New England Journal of Medicine, vol. 360, no. 13, pp. 1310-1319, 2009.

[21] R. Chou, J. M. Croswell, T. Dana et al., "Screening for prostate cancer: a review of the evidence for the U.S. preventive services 
task force," Annals of Internal Medicine, vol. 155, no. 11, pp. 762771, 2011.

[22] G. Sandblom, E. Varenhorst, J. Rosell, O. Löfman, and P. Carlsson, "Random is ed prostate cancer screening trial: 20 year follow-up," British Medical Journal, vol. 342, no. 7803, Article ID d1539, 2011.

[23] F. H. Schroder, J. Hugosson, M. J. Roobol et al., "Screening and prostate-cancer mortality in a randomized European study," The New England Journal of Medicine, vol. 360, no. 13, pp. 1320-1328, 2009.

[24] I. M. Thompson, D. K. Pauler, P. J. Goodman et al., "Prevalence of prostate cancer among men with a prostate-specific antigen level < or $=4.0$ ng per milliliter," The New England Journal of Medicine, vol. 350, no. 22, pp. 2239-2246, 2004.

[25] B. H. Gümüs, N. Neşe, M. I. Gündüz, A. R. Kandiloğlu, Y. Ceylan, and C. Büyüksu, "Does asymptomatic inflammation increase PSA? A histopathological study comparing benign and malignant tissue biopsy specimens," International Urology and Nephrology, vol. 36, no. 4, pp. 549-553, 2004.

[26] W. W. Hochreiter, "The issue of prostate cancer evaluation in men with elevated prostate-specific antigen and chronic prostatitis," Andrologia, vol. 40, no. 2, pp. 130-133, 2008.

[27] A. Thorpe and D. Neal, "Benign prostatic hyperplasia," The Lancet, vol. 361, no. 9366, pp. 1359-1367, 2003.

[28] G. P. Swanson, I. M. Thompson, and J. Basler, "Current status of lymph node-positive prostate cancer: incidence and predictors of outcome," Cancer, vol. 107, no. 3, pp. 439-450, 2006.

[29] E. Pin, C. Fredolini, and E. F. Petricoin, "The role of proteomics in prostate cancer research: biomarker discovery and validation," Clinical Biochemistry, vol. 46, no. 6, pp. 524-538, 2013.

[30] Z.-D. Han, Y.-Q. Zhang, H.-C. He et al., "Identification of novel serological tumor markers for human prostate cancer using integrative transcriptome and proteome analysis," Medical Oncology, vol. 29, no. 4, pp. 2877-2888, 2012.

[31] C. Molleken, B. Sitek, C. Henkel et al., "Detection of novel biomarkers of liver cirrhosis by proteomic analysis," Hepatology, vol. 49, no. 4, pp. 1257-1266, 2009.

[32] Y. A. Goo and D. R. Goodlett, "Advances in proteomic prostate cancer biomarker discovery," Journal of Proteomics, vol. 73, no. 10, pp. 1839-1850, 2010.

[33] J. Pang, W.-P. Liu, X.-P. Liu et al., "Profiling protein markers associated with lymph node metastasis in prostate cancer by DIGE-based proteomics analysis," Journal of Proteome Research, vol. 9, no. 1, pp. 216-226, 2010.

[34] X. Gao, J. Pang, L.-Y. Li et al., "Expression profiling identifies new function of collapsin response mediator protein 4 as a metastasis-suppressor in prostate cancer," Oncogene, vol. 29, no. 32, pp. 4555-4566, 2010.

[35] T. A. Bismar, F. Demichelis, A. Riva et al., "Defining aggressive prostate cancer using a 12-gene model," Neoplasia, vol. 8, no. 1 , pp. 59-68, 2006.

[36] S. Skvortsov, G. Schäfer, T. Stasyk et al., "Proteomics profiling of microdissected low- and high-grade prostate tumors identifies Lamin A as a discriminatory biomarker," Journal of Proteome Research, vol. 10, no. 1, pp. 259-268, 2011.

[37] J. S. Minden, S. R. Dowd, H. E. Meyer, and K. Stühler, "Difference gel electrophoresis," Electrophoresis, vol. 30, supplement 1, pp. S156-S161, 2009.

[38] B. Sitek, B. Sipos, G. Klöppel et al., "Application of fluorescence dye saturation labeling for differential proteome analysis of
1,000 microdissected cells from pancreatic ductal adenocarcinoma precursor lesions," Methods in Molecular Biology, vol. 425, pp. 1-14, 2008.

[39] S. Viswanathan, M. Ünlü, and J. S. Minden, “Two-dimensional difference gel electrophoresis," Nature Protocols, vol. 1, no. 3, pp. 1351-1358, 2006.

[40] B. Sitek, J. Lüttges, K. Marcus et al., "Application of fluorescence difference gel electrophoresis saturation labelling for the analysis of microdissected precursor lesions of pancreatic ductal adenocarcinoma," Proteomics, vol. 5, no. 10, pp. 2665-2679, 2005.

[41] R. Huttenhain, J. Malmström, P. Picotti, and R. Aebersold, "Perspectives of targeted mass spectrometry for protein biomarker verification," Current Opinion in Chemical Biology, vol. 13, no. 5-6, pp. 518-525, 2009.

[42] A. J. Percy, A. G. Chambers, J. Yang, and C. H. Borchers, "Multiplexed MRM-based quantitation of candidate cancer biomarker proteins in undepleted and non-enriched human plasma," Proteomics, vol. 13, no. 14, pp. 2202-2215, 2013.

[43] D. Domanski, A. J. Percy, J. Yang et al., "MRM-based multiplexed quantitation of 67 putative cardiovascular disease biomarkers in human plasma," Proteomics, vol. 12, no. 8, pp. 1222-1243, 2012.

[44] P. Picotti and R. Aebersold, "Selected reaction monitoringbased proteomics: workflows, potential, pitfalls and future directions," Nature Methods, vol. 9, no. 6, pp. 555-566, 2012.

[45] V. Gumpp and H. Henß, Klinisches Krebsregister KodierhilfeProstata (1), Comprehensive Cancer Center, Freiburg, Germany, 2010.

[46] A. Mortezavi, T. Hermanns, H.-H. Seifert et al., "KPNA2 expression is an independent adverse predictor of biochemical recurrence after radical prostatectomy," Clinical Cancer Research, vol. 17, no. 5, pp. 1111-1121, 2011.

[47] O.-P. Kallioniemi, U. Wagner, J. Kononen, and G. Sauter, “Tissue microarray technology for high-throughput molecular profiling of cancer," Human Molecular Genetics, vol. 10, no. 7, pp. 657-662, 2001.

[48] K. Labbus, M. Henning, E. Borkham-Kamphorst et al., "Proteomic profiling in Lipocalin 2 deficient mice under normal and inflammatory conditions," Journal of Proteomics, vol. 78, pp. 188-196, 2013.

[49] M. Berth, F. M. Moser, M. Kolbe, and J. Bernhardt, "The state of the art in the analysis of two-dimensional gel electrophoresis images," Applied Microbiology and Biotechnology, vol. 76, no. 6, pp. 1223-1243, 2007.

[50] G. Corona, E. de Lorenzo, C. Elia et al., "Differential proteomic analysis of hepatocellular carcinoma," International Journal of Oncology, vol. 36, no. 1, pp. 93-99, 2010.

[51] M. Hosako, T. Muto, Y. Nakamura et al., "Proteomic study of malignant pleural mesothelioma by laser microdissection and two-dimensional difference gel electrophoresis identified cathepsin $\mathrm{D}$ as a novel candidate for a differential diagnosis biomarker," Journal of Proteomics, vol. 75, no. 3, pp. 833-844, 2012.

[52] F. Oshita, A. Morita, H. Ito et al., "Proteomic screening of completely resected tumors in relation to survival in patients with stage I non-small cell lung cancer," Oncology Reports, vol. 24, no. 3, pp. 637-645, 2010.

[53] D. A. Megger, T. Bracht, M. Kohl et al., "Proteomic differences between hepatocellular carcinoma and nontumorous 
liver tissue investigated by a combined gel-based and labelfree quantitative proteomics study," Molecular and Cellular Proteomics, vol. 12, no. 7, pp. 2006-2020, 2013.

[54] W. Remmele and H. E. Stegner, "Recommendation for uniform definition of an immunoreactive score (IRS) for immunohistochemical estrogen receptor detection (ER-ICA) in breast cancer tissue," Pathologe, vol. 8, no. 3, pp. 138-140, 1987.

[55] N. Selevsek, M. Matondo, M. S. Carbayo, R. Aebersold, and B. Domon, "Systematic quantification of peptides/proteins in urine using selected reaction monitoring," Proteomics, vol. 11, no. 6, pp. 1135-1147, 2011.

[56] M. A. Kuzyk, D. Smith, J. Yang et al., "Multiple reaction monitoring-based, multiplexed, absolute quantitation of 45 proteins in human plasma," Molecular and Cellular Proteomics, vol. 8, no. 8, pp. 1860-1877, 2009.

[57] D. Hanahan and R. A. Weinberg, "Hallmarks of cancer: the next generation," Cell, vol. 144, no. 5, pp. 646-674, 2011.

[58] L. C. Fang, M. Dattoli, A. Taira, L. True, R. Sorace, and K. Wallner, "Prostatic acid phosphatase adversely affects causespecific survival in patients with intermediate to high-risk prostate cancer treated with brachytherapy," Urology, vol. 71, no. 1, pp. 146-150, 2008.

[59] A. Taira, G. Merrick, K. Wallner, and M. Dattoli, "Reviving the acid phosphatase test for prostate cancer," Oncology, vol. 21, no. 8, pp. 1003-1010, 2007.

[60] H. Y. Kong and J. Byun, "Emerging roles of human prostatic acid phosphatase," Biomolecules and Therapeutics, vol. 21, no. 1, pp. 10-20, 2013.

[61] J. Ellerhorst, P. Troncoso, X.-C. Xu, J. Lee, and R. Lotan, "Galectin-1 and galectin-3 expression in human prostate tissue and prostate cancer," Urological Research, vol. 27, no. 5, pp. 362367, 1999.

[62] F. A. Van Den Brûle, D. Waltregny, F.-T. Liu, and V. Castronovo, "Alteration of the cytoplasmic/nuclear expression pattern of Galectin-3 correlates with prostate carcinoma progression," International Journal of Cancer, vol. 89, no. 4, pp. 361-367, 2000.

[63] A. S. Merseburger, M. W. Kramer, J. Hennenlotter et al., "Involvement of decreased galectin-3 expression in the pathogenesis and progression of prostate cancer," Prostate, vol. 68, no. 1, pp. 72-77, 2008.

[64] A. B. Gutman and E. B. Gutman, "An "acid" phophatase occuring in the serum of patients with metastasizing carcinoma of the prostate gland," The Journal of Clinical Investigation, vol. 17, no. 4, pp. 473-478, 1938.

[65] T. Bhavsar, P. McCue, and R. Birbe, "Molecular diagnosis of prostate cancer: are we up to age?" Seminars in Oncology, vol. 40, no. 3, pp. 259-275, 2013.

[66] J. F. Bogdanowicz, F. M. Bentvelsen, R. Oosterom, and F. H. Schroeder, "Evaluation of prostate-specific antigen and prostatic acid phosphatase in untreated prostatic carcinoma and benign prostatic hyperplasia," Scandinavian Journal of Urology and Nephrology, Supplement, vol. 138, pp. 97-103, 1991.

[67] H. Ahmed, F. Cappello, V. Rodolico, and G. R. Vasta, "Evidence of heavy methylation in the galectin 3 promoter in early stages of prostate adenocarcinoma: development and validation of a methylated marker for early diagnosis of prostate cancer," Translational Oncology, vol. 2, no. 3, pp. 146-156, 2009.

[68] S. Califice, V. Castronovo, M. Bracke, and F. van den Brǔle, "Dual activities of galectin-3 in human prostate cancer: tumor suppression of nuclear galectin-3 vs tumor promotion of cytoplasmic galectin-3," Oncogene, vol. 23, no. 45, pp. 7527-7536, 2004.
[69] M. R. De Melo-Júnior, J. L. S. Araújo-Filho, C. A. B. Lins, N. T. De Pontes-Filho, and L. B. De Carvalho Jr., "Immobilization of anti-galectin-3 onto polysiloxane-polyvinyl alcohol disks for tumor prostatic diseases diagnosis," Applied Biochemistry and Biotechnology, vol. 160, no. 8, pp. 2198-2207, 2010.

[70] H. Ahmed, "Promoter methylation in prostate cancer and its application for the early detection of prostate cancer using serum and urine samples," Biomarkers in Cancer, vol. 2010, no. 2, pp. 17-33, 2010.

[71] J. Fan, D. Yan, M. Teng et al., "Digital transcript profile analysis with aRNA-LongSAGE validates FERMT1 as a potential novel prognostic marker for colon cancer," Clinical Cancer Research, vol. 17, no. 9, pp. 2908-2918, 2011.

[72] N. Miyoshi, H. Ishii, K. Mimori, M. Sekimoto, Y. Doki, and M. Mori, "SCRN1 is a novel marker for prognosis in colorectal cancer," Journal of Surgical Oncology, vol. 101, no. 2, pp. 156-159, 2010.

[73] T. Suda, T. Tsunoda, N. Uchida et al., "Identification of secernin 1 as a novel immunotherapy target for gastric cancer using the expression profiles of cDNA microarray," Cancer Science, vol. 97, no. 5, pp. 411-419, 2006.

[74] E. Sabo, P. A. Meitner, R. Tavares et al., "Expression analysis of barrett's esophagus-associated high-grade dysplasia in laser capture microdissected archival tissue," Clinical Cancer Research, vol. 14, no. 20, pp. 6440-6448, 2008.

[75] Y. Suehara, N. Tochigi, D. Kubota et al., "Secernin-1 as a novel prognostic biomarker candidate of synovial sarcoma revealed by proteomics," Journal of Proteomics, vol. 74, no. 6, pp. 829842,2011

[76] C. Ruiz, D. R. Holz, M. Oeggerli et al., "Amplification and overexpression of vinculin are associated with increased tumour cell proliferation and progression in advanced prostate cancer," Journal of Pathology, vol. 223, no. 4, pp. 543-552, 2011.

[77] K. Thorsen, K. D. Sørensen, A. Brems-Eskildsen et al., "Alternative splicing in colon, bladder, and prostate cancer identified by exon array analysis," Molecular \& Cellular Proteomics, vol. 7, no. 7, pp. 1214-1224, 2008.

[78] S.-L. Liang and D. W. Chan, "Enzymes and related proteins as cancer biomarkers: a proteomic approach," Clinica Chimica Acta, vol. 381, no. 1, pp. 93-97, 2007.

[79] T. Kondo, "Tissue proteomics for cancer biomarker development-laser microdissection and 2D-DIGE," Journal of Biochemistry and Molecular Biology, vol. 41, no. 9, pp. 626-634, 2008.

[80] G. Chen, T. G. Gharib, C.-C. Huang et al., "Discordant protein and mRNA expression in lung adenocarcinomas," Molecular \& Cellular Proteomics, vol. 1, no. 4, pp. 304-313, 2002.

[81] D. K. Ornstein and E. F. Petricoin III, "Proteomics to diagnose human tumors and provide prognostic information," Oncology, vol. 18, no. 4, pp. 521-532, 2004.

[82] K. S. Lilley, A. Razzaq, and P. Dupree, "Two-dimensional gel electrophoresis: Recent advances in sample preparation, detection and quantitation," Current Opinion in Chemical Biology, vol. 6, no. 1, pp. 46-50, 2002.

[83] S. A. Dyshlovoy, I. Naeth, S. Venz et al., "Proteomic profiling of germ cell cancer cells treated with aaptamine, a marine alkaloid with antiproliferative activity," Journal of Proteome Research, vol. 11, no. 4, pp. 2316-2330, 2012.

[84] N. Chignard and L. Beretta, "Proteomics for hepatocellular carcinoma marker discovery," Gastroenterology, vol. 127, supplement 1, no. 5, pp. S120-S125, 2004. 
[85] N. A. Karp, R. Feret, D. V. Rubtsov, and K. S. Lilley, "Comparison of DIGE and post-stained gel electrophoresis with both traditional and SameSpots analysis for quantitative proteomics," Proteomics, vol. 8, no. 5, pp. 948-960, 2008.

[86] J. F. Timms and R. Cramer, "Difference gel electrophoresis," Proteomics, vol. 8, no. 23-24, pp. 4886-4897, 2008. 


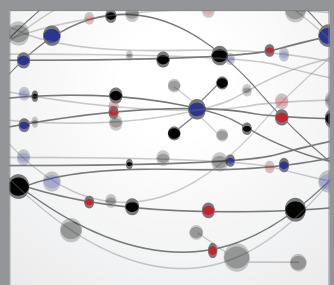

The Scientific World Journal
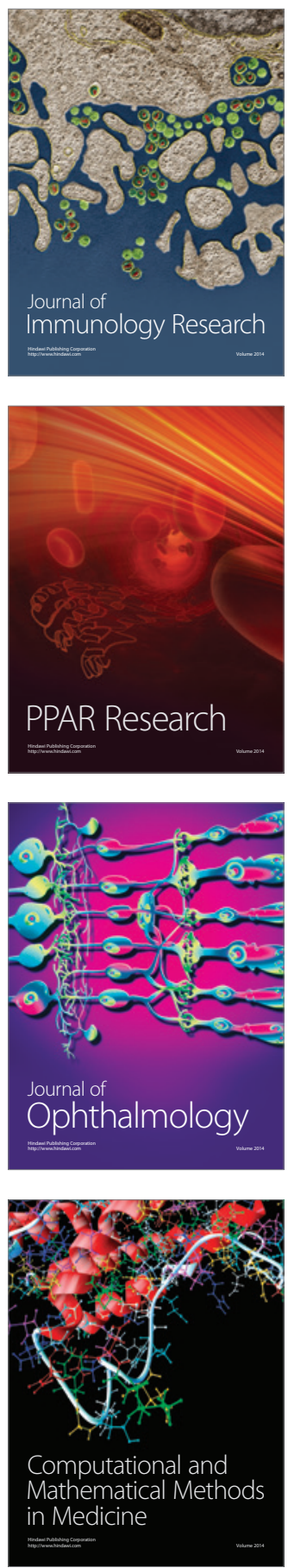

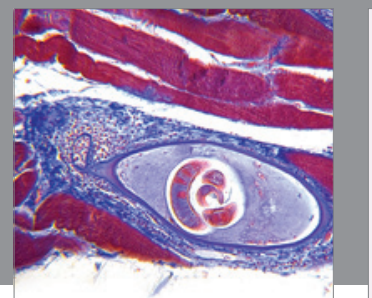

Gastroenterology

Research and Practice
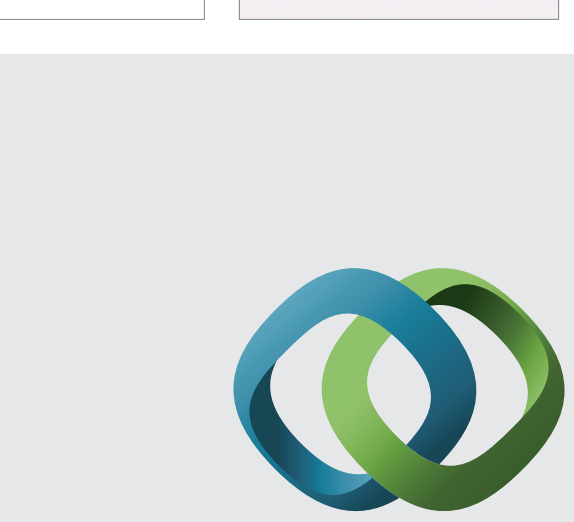

\section{Hindawi}

Submit your manuscripts at

http://www.hindawi.com
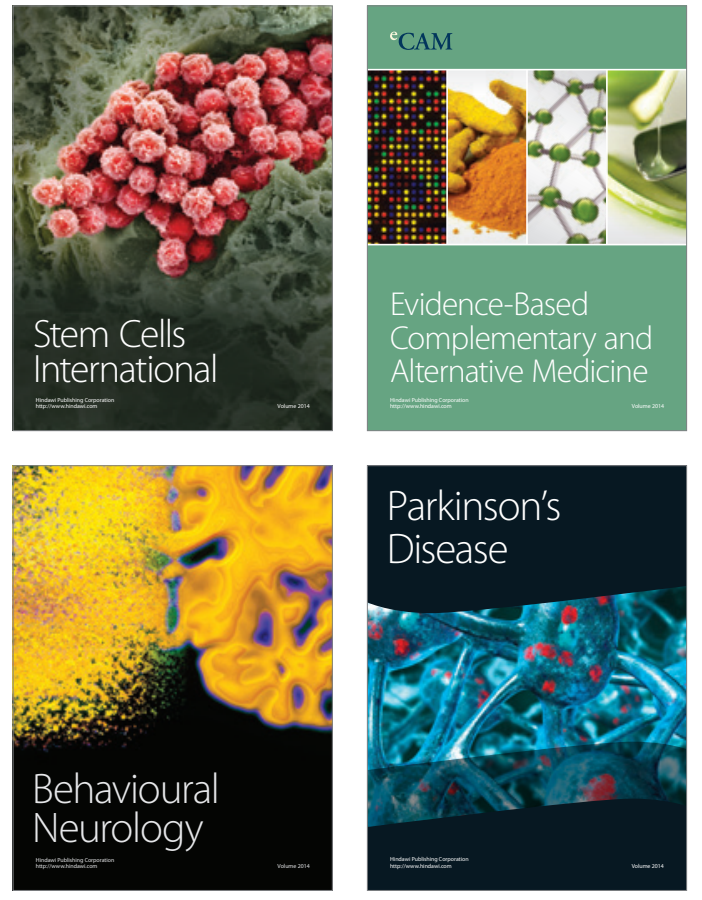
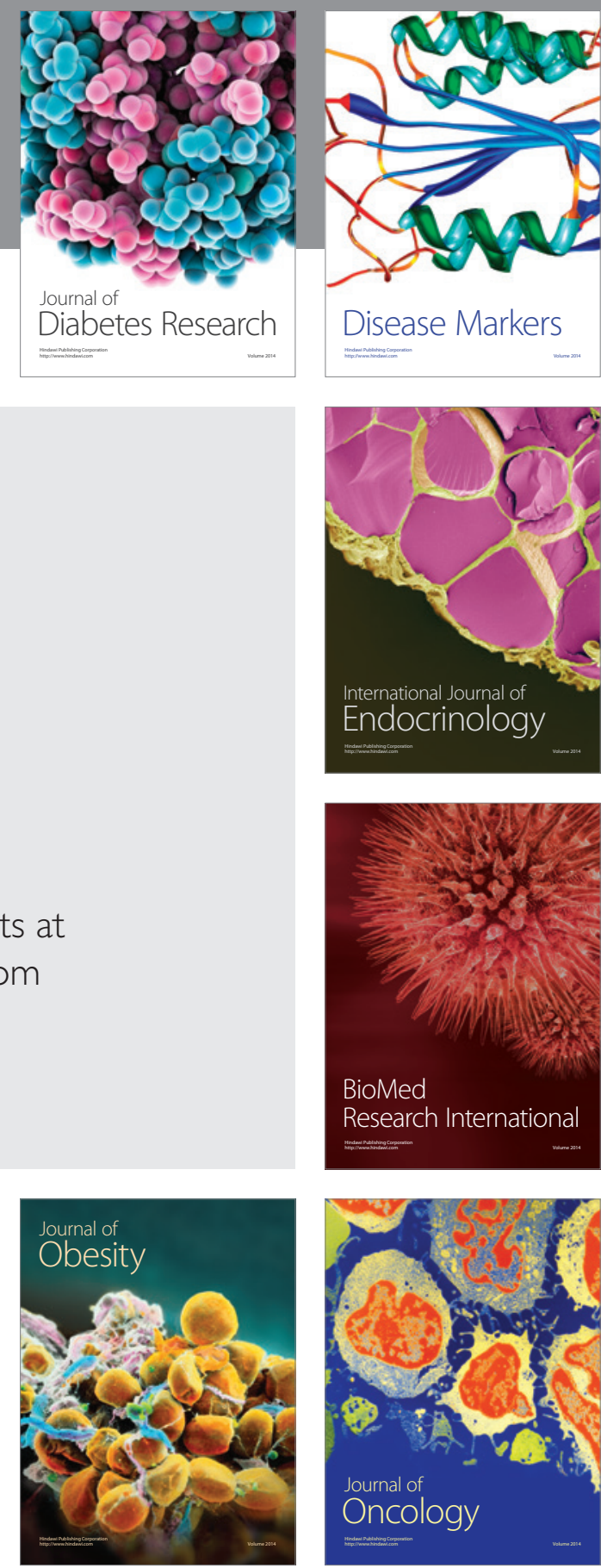

Disease Markers
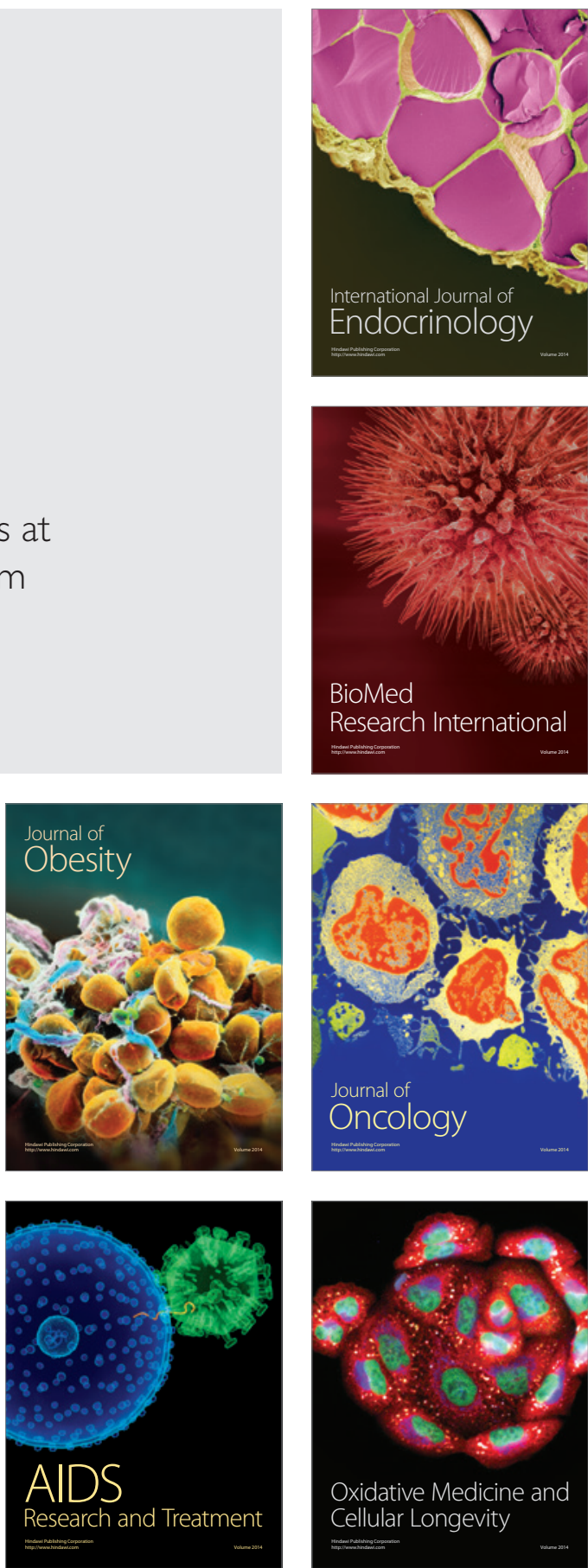